Illinois State University

ISU ReD: Research and eData

Theses and Dissertations

5-23-2016

\title{
To Promote or Prevent When Near or Far: Exploring Regulatory Focus in Geographically-close and Long-distance Relationships
}

Adam James Hampton

Illinois State University, adamjhampton@outlook.com

Follow this and additional works at: https://ir.library.illinoisstate.edu/etd

Part of the Communication Commons, and the Social Psychology Commons

\section{Recommended Citation}

Hampton, Adam James, "To Promote or Prevent When Near or Far: Exploring Regulatory Focus in Geographically-close and Long-distance Relationships" (2016). Theses and Dissertations. 570. https://ir.library.illinoisstate.edu/etd/570

This Thesis is brought to you for free and open access by ISU ReD: Research and eData. It has been accepted for inclusion in Theses and Dissertations by an authorized administrator of ISU ReD: Research and eData. For more information, please contact ISUReD@ilstu.edu. 


\title{
TO PROMOTE OR PREVENT WHEN NEAR OR FAR: EXPLORING REGULATORY FOCUS IN GEOGRAPHICALLY-CLOSE AND LONG-DISTANCE RELATIONSHIPS
}

\author{
Adam J. Hampton
}

\section{Pages}

No research to date has examined how regulatory focus theory applies to relationships that are maintained long-distance, nor if individuals' regulatory orientations differ in predicting relationship maintenance efforts between relationships that are geographically-close and those that are long-distance. The current study explores the communication efforts, ideal perceptions, and regulatory behaviors of individuals as a function of their regulatory focus (promotion focus vs. prevention focus) and relationship type (geographically-close vs. long-distance). One hundred eighty participants completed a survey that assessed their relationship type, regulatory focus, and relationship maintenance efforts (i.e., communications, perceptions, and behavior). Overall, it was found that individuals in long-distance relationships, compared to individuals in geographically-close relationships, engage in more frequent communication efforts, more self-idealized perceptions, and less self-regulation behaviors. Regarding regulatory orientations, those with a high degree of promotion focus, compared to those with a low degree of promotion focus, reported more intimate communication, more idealized 
perceptions of their partners and themselves, and less behavioral regulation of their partners and themselves. Alternatively, those with a high degree of prevention focus, compares to those with a low degree of prevention focus, reported less frequent communication, less partner-idealized perceptions, and more behavioral regulation of their partners and themselves. While regulatory orientations did not differ as a function of relationship type, implications are discussed pertaining to how the rapid evolution of communication technology has changed the way in which individuals maintain their relationship.

KEYWORDS: Romantic Relationships, Regulatory Focus, Long-distance, Communication, Perception, Behavior 
TO PROMOTE OR PREVENT WHEN NEAR OR FAR: EXPLORING

REGULATORY FOCUS IN GEOGRAPHICALLY-CLOSE AND

LONG-DISTANCE RELATIONSHIPS

ADAM J. HAMPTON

A Thesis Submitted in Partial

Fulfillment of the Requirements

for the Degree of

MASTER OF SCIENCE

Department of Psychology

ILLINOIS STATE UNIVERSITY

2016 
(C) 2016 Adam J. Hampton 
TO PROMOTE OR PREVENT WHEN NEAR OR FAR: EXPLORING

REGULATORY FOCUS IN GEOGRAPHICALLY-CLOSE AND

LONG-DISTANCE RELATIONSHIPS

ADAM J. HAMPTON

COMMITTEE MEMBERS:

Susan Sprecher, Co-Chair

Marla Reese-Weber, Co-Chair

J. Scott Jordan 


\section{ACKNOWLEDGMENTS}

I would like to thank my family, friends, mentors, and loved ones both geographically-close and long-distance, whose continued support, dedication, and encouragement have instilled in me the grit and determination needed to wade through this amazing journey. I thank Kyle Teno for his love and all the laughs we have shared in the past two years. I thank my parents, David and Susan Hampton, who taught to me the values of work ethic, independence, and compassion. Finally, I thank my committee Drs. Sue Sprecher, Marla Reese-Weber, and Scott Jordan - who have provided me academic guidance and mentorship over the years (among tolerating my neurotic tendencies). I credit my successes in life to all of the above individuals and am forever grateful to each of them; they have shaped me into someone that I have grown to be truly proud of. Time and time again - thank you.

A. J. H. 


\section{CONTENTS}

Page

ACKNOWLEDGMENTS $\quad$ i

CONTENTS

TABLES $\quad$ V

FIGURES $\quad$ vi

CHAPTER

I. INTRODUCTION 1

Statement of the Problem 1

Literature Review 4

Regulatory Focus Theory 4

Relationship Maintenance: Communication,

Perceptions, and Behavior $\quad 13$

Relationship communication: the impact of computer-mediated communication $\quad 14$

Relationship perceptions: the ideal standards model

Relationship behavior: the role of the self and the partner 20

The Current Research 25

Hypotheses on Relationship Communication 25

Hypotheses on Relationship Perceptions 26

Hypotheses on Relationship Behavior 28

II. STUDY DESIGN 30

$\begin{array}{ll}\text { Participants } & 30\end{array}$

Measures $\quad 33$ 
Demographics $\quad 33$

Regulatory Focus $\quad 34$

Relationship Communication 34

CMC quantity $\quad 34$

CMC intimacy $\quad 35$

Relationship Perceptions 35

Partner-IPC 36

Self-IPC 36

$\begin{array}{ll}\text { Relationship Behavior } & 37\end{array}$

Partner-regulation $\quad 37$

Self-regulation $\quad 37$

Quality Checks 37

$\begin{array}{ll}\text { Procedure } & 38\end{array}$

$\begin{array}{lll}\text { III. RESULTS } & 40\end{array}$

$\begin{array}{ll}\text { Preliminary Analyses } & 40\end{array}$

Primary Analyses 43

Relationship Communication (Hypothesis 1) 44

CMC quantity $\quad 44$

CMC intimacy 46

Relationship Perceptions (Hypothesis 2) 46

Partner-IPC 46

Self-IPC 47

Relationship Behavior (Hypothesis 3) 49

Partner-regulation $\quad 49$

Self-regulation 49

$\begin{array}{lll}\text { IV. DISCUSSION } & 51\end{array}$

Relationship Communication: The Evolution of Computermediated Communication 
Relationship Perceptions: Bridging the Gap between

Communication and Behavior

Relationship Behavior: The Misconception of Independence

62

Limitations, Strengths, and Directions for Future Research

Concluding Remarks
64

69

71

81 


\section{TABLES}

Table $\quad$ Page

1. Demographic Information 32

2. Descriptive Results and Correlations among Key Variables of Total Sample

3. Correlations among the Intimacy of CMC Modes and Relationship Perceptions (GCRs vs. LDRs) 


\section{FIGURES}

$\begin{array}{lll}\text { Figure } & \text { Page }\end{array}$

1. General Model of Relationship Cognition 18

2. Degree of CMC Quantity and CMC Intimacy as a Function of Relationship Type

3. Low (-1 SD) and High (+1 SD) Degrees of Participants' Regulatory Orientations as Predictors of Relationship Perceptions and Behavior:

(a) Partner-IPC, (b) Self-IPC, (c) Partner-regulation, (d) Self-regulation 48 


\section{CHAPTER I}

\section{INTRODUCTION}

\section{Statement of the Problem}

There is a need for increased research on the various facets about long-distance relationships (LDR), yet the field of relationship science continues to focus primarily on the readily available and easily accessible individuals in geographically-close relationships (GCR; Rohlfing, 1995). The Center for the Study of Long Distance Relationships reported that, in 2005, roughly 3.57 million $(2.9 \%)$ of all marriages in the United States were long-distance, which was a $23.5 \%$ increase compared to five years prior. According to census data at the time, $10 \%$ of newlyweds reported being in a LDR at some point during their first three years of marriage. Approximately $14 \%$ of all sampled individuals in non-marital relationships reported being in a LDR (The Center, 2005). Though difficult to obtain consistent and accurate estimates (due to the fluidity of college dating), it has been estimated that anywhere between 20 and $40 \%$ of college relationships are long-distance in nature, with $75 \%$ of graduates reported to have been in a LDR at some point during college (Merolla, 2010). Taken together, this would mean that, in 2005, approximately 14-15 million individuals in the United States were in a LDR. Though these results are dated, more recent research has supported that the proportion of individuals in long-distance relationships has grown (Cemalcilar, 2008; 
Firmin, Firmin, \& Merical, 2013; Stafford, 2010), due to the advancements in technology and increased accessibility of computer-mediated communication in the past decade (i.e., texting, video chat, instant messaging), which aid in alleviating some of the communication stresses that occur in LDRs.

With the growing numbers of LDRs, it is imperative to increase research on whether various facets related to relationship maintenance that are currently understood in the context of GCRs can be extended to relationships that are less proximal. Dindia and Canary (1993) describe relationship maintenance in four distinct ways. First and foremost, relationship maintenance is the act of keeping a relationship in existence (i.e., not broken up, separated, or divorced). Second, maintaining one's relationship not only aims to keep the relationship from terminating, but also to keep the relationship sustained in a specific condition; that is, the qualities that are important in a relationship (i.e., trust, intimacy, closeness) must be preserved and in a steady state. Third, to maintain a relationship is to keep it in a state of satisfaction. The final definition of relationship maintenance is to repair the relationship when it fluctuates from the standards that one has for an ideal relationship; additionally, Davis (1973) explained that relationship repair can be done through preventative or corrective manners. Although there may be overlap among these four definitions, each aids in conceptualizing relationship maintenance.

Three important facets of relationship maintenance that have been thoroughly investigated in GCRs are the communication efforts that partners engage in to maintain their relationship (Coyne, Stockdale, Busby, Iverson, \& Grant, 2011), the perceptions that individuals have about their relationship (Simpson, Fletcher, \& Campbell, 2001), and the behaviors they enact in response to these perceptions (Fitzsimons \& Finkel, 2011; 
Overall \& Sibley, 2008). One predominant framework used to conceptualize these three facets in romantic relationships is regulatory focus theory (Higgins, 1996a, 1997). Regulatory focus theory posits that when individuals engage in regulatory (behavioral) processes in relation to their romantic partner, they are faced with the task of embracing one of two discrete foci: a promotion focus or a prevention focus (Higgins, 1996a, 1997, 1998). Individuals who are more promotion-oriented tend to focus on what the couple would like to accomplish within their relationship in order to increase overall relationship satisfaction, whereas individuals who are more prevention-oriented tend to focus on what the couple would like to prevent in their relationship in order to decrease overall relationship dissatisfaction (Lackenbauer \& Campbell, 2012).

No research to date has examined how regulatory focus theory applies to LDRs, nor if one's own ideal standards and the perceptions one holds of a partner's ideal standards differ between GCRs to LDRs. Ideal standards are the beliefs that an individual holds about the qualities that his or her partner or relationship should "ideally" have, which can also be causally related to the communicative efforts, perceptions, and regulatory behavior that an individual enacts in an ongoing relationship (Fletcher, Simpson, Thomas, \& Giles, 1999). The current study explores the communication efforts, ideal perceptions, and regulatory behaviors of individuals as a function of their regulatory focus (promotion focus vs. prevention focus) and relationship type (GCRs vs. LDR). The findings contribute to the substantial need and call for research on LDRs and provide a more comprehensive examination of regulatory focus theory applied to romantic relationships. 


\section{Literature Review}

In the comprehensive review of the literature that follows, I first summarize regulatory focus theory and the previous work from which it originated, followed by a summary of how this theoretical framework has been utilized in many studies applied to romantic relationships. Following this, three aspects of relationship maintenance (communication, perceptions, and behavior) that have been relatively unexplored in previous applications of regulatory focus theory will be outlined. From this, hypotheses will be presented on how the communication efforts, perceptions, and behavior that exist in romantic relationships will vary as a function of one's regulatory focus (promotion focus vs. prevention focus) and relationship type (GCR vs LDR).

\section{Regulatory Focus Theory}

Before regulatory focus theory is presented, the theory from which it originated must be summarized - self-discrepancy theory (Higgins, 1987, 1989). According to selfdiscrepancy theory, there are three basic domains of the self: the actual self, the ideal self, and the ought self (Higgins, 1987). The actual self is a representation of all of the attributes and characteristics that individuals believe they possess. The ideal self is a representation of all the attributes and characteristics that individuals would ideally like to possess. Finally, the ought self is a representation of all the attributes and characteristics that individuals believe they should possess. Though these representations had been developed by earlier researchers (Piers \& Singer, 1971; Rogers, 1961), Higgins $(1987,1989)$ argued that merely differentiating among the various representations of the self is not sufficient to describe one's actual perceptions and behavioral motivations. Thus, self-discrepancy theory posited that there must be differentiation between two 
points of view, or "standpoints", on which the self is being viewed - the standpoint that Partner A has of his or her own self and the standpoint held by Partner B (e.g., a romantic partner, friend, family member) of Partner A.

Considering the standpoints held by both the self and the partner, six distinct "self-state" representations can be formed - actual/own, actual/other, ideal/own, ideal/other, ought/own, and ought/other (Higgins, 1987). The actual self-states (actual/own, actual/other) comprise one's self-concept; that is, an individual's selfconcept is formed by taking two perspectives into consideration - how Partner A perceives his or her self and how Partner A believes Partner B perceives his or her self. The latter four self-states comprise one's self-guides, which direct his or her overall behavior and motives; that is, an individual's self-guide is formed by taking two perspectives into consideration - how Partner A believes he or she ideally could (idealself guide) or should (ought-self guide) behave and in what ways Partner B believes Partner A ideally could or should behave (held from the perspective of Partner A). Higgins (1987) believed that human behavior takes root in attempting to match one's self-concept as closely as possible to one's self-guides. Any perceptions of discrepancy between one's self-concept and self-guides is what drives individuals to employ behavior aimed to reduce such discrepancies.

Later, Higgins (1996a) expanded upon self-discrepancy theory, explaining that perceptions of the self are not the only thoughts that drive individuals to regulate their behavior. According to Higgins' new theory, regulatory focus theory, individuals regulate their behavior to achieve certain outcomes or goals in life (i.e., goal pursuit); however, there are two distinct regulatory foci, or orientations, which individuals can embrace to 
guide them in their pursuits - a promotion focus or a prevention focus. These foci are not static identities that one holds, nor are they individual difference variables associated with certain personality types. Rather, regulatory focus is a fluid state of mind, in which each regulatory orientation is concerned with differential motivations (Higgins, 1997). When embracing a promotion focus, the state of mind is of eagerness and growth and is concerned with "promoting" positive outcomes. When embracing a prevention focus, the state of mind is of vigilance and security and is concerned with "preventing" negative outcomes. As humans, we have basic needs for both growth and security (Higgins, 1996b), so it would be unreasonable to assume that one would adopt a specific focus for every situation that calls for behavioral regulation.

Indeed, individuals embrace each regulatory foci at different times in life, depending on the situations or circumstances they are faced with. In many circumstances, regulatory actions can conflict with the behavior and goal pursuits of a significant other; this is perhaps most common in romantic relationships. Lackenbauer and Campbell (2012) stated that in romantic relationships, some needs take their root in growth, a promotion-focused concern of relationship maintenance, which is specifically focused on what the romantic couple would like to strive for within their relationship (e.g., trust, monogamy, agreements, etc.). Additionally, some needs take their root in security, a prevention-focused concern of relationship maintenance, which is specifically focused on what the romantic couple would like to avoid within their relationship (e.g., lies, infidelity, arguments, etc.). Despite the need for both growth and security in romantic relationships, however, people do tend to prefer and utilize one regulatory state over the other in the majority of their regulatory decisions (Higgins et al., 2001). Across five 
studies, Higgins et al. found that those who reported to have implemented more promotion-focused means of goal attainment in their past goal pursuits, as compared to more prevention-focused means, were more likely to embrace such a focus for various decision-making tasks. The same effect was found for those who reported to have implemented more prevention-focused means of goal attainment in their past goal pursuits. Overall, Higgins et al. suggested that one's regulatory focus is reinforced; that is, succeeding in goal pursuits from utilizing one regulatory foci in the past predicts subsequent utilization of such means in future pursuits.

Adherence to primarily one regulatory focus over the other can result in negative effects on relationship maintenance, however. Those who place high emphasis on promotion ideals can become overly focused on obtaining gratifying outcomes and, in the process, ignore other important details and behaviors that are important for relationship security (e.g., indicators of partner unhappiness and emotional withdrawal; Grant \& Higgins, 2003). Additionally, promotion-focused orientations often lead individuals to hope and ask for more out of their romantic partner than they can feasibly provide, thus engaging in a corrective manner of risk regulation (Overall \& Simpson, 2013; Winterheld \& Simpson, 2011). For example, imagine that an individual (whom will be referred to as Lynette throughout this paper) expects her partner (whom will be referred to as Jason) to work full time hours, take their kids to and from school, have dinner ready when she gets home from work, and maintain the household chores. Jason may have a hard time living up to these expectations, resulting in disappointment and bitter attitudes from Lynette. On the other hand, Winterheld and Simpson (2011) noted that those who are too preventionfocused in their orientation can withdraw from any type of perceived hostility or 
regulating attempt from their partner, viewing it as an attack to their character, thus engaging in a self-protective manner of risk regulation. For example, if after some time of being continually asked why the household chores have not been completed, Jason may begin to withdraw from any regulatory attempts from Lynette, thwarting any progress to be made for both partners in the process. Winterheld and Simpson urge that striking a balance between promotion and prevention orientations provides the most opportunity to facilitate relationship growth and relationship security.

Indeed, both growth and security are important to relationship maintenance. Molden, Lucas, Finkel, Kumashiro, and Rusbult (2009) examined the associations between married individuals' personal well-being and their perceived support (from their romantic partner) for both promotion-focused and prevention-focused goals. Though perceived support for each type of goal independently predicted personal well-being, the association was strongest when both types of goals were perceived to be supported. Through further analysis, Molden et al. found that support for promotion-focused goals (e.g., validating one's dreams and aspirations) instilled feelings of trust between partners, while support for prevention-focused goals (e.g., acknowledging one's obligations and responsibilities) instilled feelings of commitment. Though no research has examined the impact that these regulatory motivations may have on trust and commitment in LDRs, it would be reasonable to assume that support for each type of goal - those that instill trust (promotion-focused goals) and those that instill commitment (prevention-focused goals) - would be especially important for those in a LDR. In fact, through survey research, Dainton and Aylor (2001) found that those in a LDR with some face-to-face contact 
reported significantly more trust in and commitment to the relationship than did those in a GCR.

With both trust and commitment being beneficial to relationship maintenance in both GCRs and LDRs, it is important to examine how pairings of regulatory foci (similar vs. complementary) between relationship partners impact romantic couples. Upon examining the associations (via multilevel modeling) between couples' regulatory orientations, goal congruence (i.e., commitment to joint goal-pursuit), and relationship well-being, Bohns et al. (2013) found that individuals who shared the same regulation method as their partner reported a greater degree of goal congruence, which predicted relationship well-being between the partners. It can be understood, then, why Bohns and Higgins (2011) found that people prefer when their romantic partner embodies the same regulatory orientation as they do.

However, this is not to say that partners who hold different regulatory foci cannot be compatible; in fact, quite the opposite can occur. If one partner is more promotionfocused in his or her regulatory orientation while the other is more prevention-focused, it may give the dyad the opportunity to "divide and conquer" the various tasks needed to accomplish a particular goal, as suggested by Bohns and Higgins (2011, p. 520). Bohns and Higgins tested this idea by presenting participants with a forced-choice decision between an eager (promotion-focused) or a vigilant (prevention-focused) partner for two different tasks - a unitary task (roles and responsibilities cannot be divided between two people) of watching a movie and a divisible task (roles and responsibilities can be divided between two people) of cooking a meal. Bohns and Higgins (2011) found that the majority of participants, regardless of their own measured regulatory focus, preferred the 
partner with the same focus for the unitary task and the partner with the opposite focus for the divisible task. Indeed, when one is matched with a complementary (oppositefocus) partner for a divisible task, both members of the dyad have the ability to act in their preferred regulatory style, rather than having to bend and cater to their partner's style. In sum, both similar and complementary pairings of regulatory foci in romantic relationships can predict positive outcomes, with each pairing being advantageous in certain situations. Pairings of similarity tend to be of value when partners are attempting to agree on joint goals in the relationship or when attempting to avoid conflict, while pairings of complementarity tend to be of value when interpersonal coordination is required for joint goals in the relationship (Bohns et al., 2013).

Past research has found that each regulatory orientation may elicit different emotions when one either achieves or does not achieve his or her goals (Roseman, 1984; Stein \& Jewett, 1982; Winterheld \& Simpson, 2011). As stated previously, promotionfocused individuals are especially concerned with obtaining positive outcomes in life. If these positive outcomes are obtained, the regulator likely experiences states of general happiness (Winterheld \& Simpson, 2011); dejection-related emotions (e.g., depression, disappointment) are often experienced if the individual does not achieve such pursuits (Roseman, 1984). Alternatively, prevention-focused individuals are especially concerned with avoiding negative outcomes. If these negative outcomes are avoided, the regulator likely experiences states of general quiescence (Winterheld \& Simpson, 2011); agitationrelated emotions (e.g., anxiety, fear) are often experienced if the individual is unable to prevent such detriments (Stein \& Jewett, 1982). Such implications should be considered when comparing GCRs and LDRs. Many recent scholars (Cameron \& Ross, 2007; 
Maguire \& Kinney, 2010; Merolla, 2012; Pistole, 2010; Sahlstein, 2006) have suggested that those in a LDR are at an increased risk of distress, relational uncertainty, and anxiety (i.e., agitation-related emotions) compared to those in a GCR. Thus, geographic separation could cause increased levels of prevention-focused motivations in LDRs.

These findings on emotions related to each regulatory foci, when translated to an event within a romantic relationship, still hold true. For example, Winterheld and Simpson (2011) designed a study in which individuals in romantic relationships, after completing a measure to assess their regulatory focus, were presented with a hypothetical scenario. In this scenario, participants were asked to imagine a situation in which they have had a particularly bad day and have a desire to speak with their romantic partner in order to vent about some of the problems they had experienced. For half of the participants, the scenario ended with their partner never responding to any of their texts or calls; for the other half, their partner showed up at their house with a surprise present. Subjects in the negative ending scenario who were more promotion-oriented (compared to those with lower promotion focus scores) reported that they would likely experience more dejection-related emotions from the event, while those who were more preventionoriented (compared to those with lower prevention focus scores) reported that they would likely experience more agitation-related emotions from the event. Interestingly, in the positive scenario, those with a promotion focus, as compared to those with a prevention focus, responded with more happiness-related emotions. In fact, across the four studies conducted by Winterheld and Simpson (2011), promotion-focused individuals (or, in the case of two of the studies, those primed with a promotion focus) consistently held more favorable perceptions of partner supportiveness and less favorable perceptions of partner- 
distancing behavior than prevention-focused individuals (or those primed with a prevention focus).

Though both a promotion and prevention foci can predict certain emotions experienced in a particular event, the regulatory focus that individuals choose to adopt can vary by the type of event with which they are faced. In a study conducted by Lackenbauer and Campbell (2012), individuals were primed with one of two tasks - (1) to think about ways in which their partner was discrepant from the ideals they held for a romantic partner, or (2) to think about ways in which they themselves were discrepant from the ideals they believed that their partner held for a romantic partner. Following this, subjects completed a lexical decision task in which they had to quickly respond to a series of letter strings. Subjects were to indicate (as quickly as possible) if the string of letters they briefly saw was a word (being dejection-related emotions, agitation-related emotions, or neutral words) or a non-word. Individuals who were assigned to the partnerdiscrepancy prime responded significantly more quickly to dejection-related emotions (i.e., a promotion-focused approach to emotion regulation) than did individuals assigned to the self-discrepancy prime. In contrast, individuals who were assigned to the selfdiscrepancy prime responded significantly more quickly to agitation-related emotions (i.e., a prevention-focused approach to emotion regulation) than did individuals assigned to the partner-discrepancy prime.

From these findings, it could be suggested that individuals who score higher in promotion ideals may have an increased sensitivity to partner-discrepancies, whereas individuals who score higher in prevention ideals may have an increased sensitivity to self-discrepancies. In consideration of relationship type, it could be predicted that 
individuals in a LDR would be more sensitive to both self- and partner-discrepancies because of factors related to idealization, which is discussed in the following section. In conclusion, the regulatory focus that one chooses to embrace in a romantic relationship can predict individual outcomes related to behavioral motivations and emotions, in addition to dyadic outcomes related to relationship maintenance. Left to be explored is whether some of the individual and dyadic outcomes related to regulatory motivations can differentially impact strategies of relationship maintenance in geographically-close and long-distance relationships.

\section{Relationship Maintenance: Communication, Perceptions, and Behavior}

Relationship maintenance, or engaging in behaviors that increase overall relationship satisfaction, has been found to be challenging for individuals in a LDR. Van Horn et al. (1997) analyzed survey responses regarding maintenance processes in relationships from individuals in either a GCR or a LDR. Individuals in a LDR, compared to those in a GCR, reported less companionship, self-disclosure, and certainty in the longevity of their relationship. Three other components of relationship maintenance communication, perceptions, and behavior - are met with unique challenges for those in a LDR. For those in a LDR, compared to those with relationships that are more proximal, intimate communication is often mediated through technology (Kirkpatrick, 2007), perceptions of one's partner are often idealized (Guerrero, Andersen, \& Afifi, 2013), and fewer opportunities are available for behavioral regulation with one's partner (Stafford \& Reske, 1990). However, only a small amount of past research has compared these phenomena between GCRs and LDRs; less is known, still, on whether these aspects of relationship maintenance may differ as a function of one's regulatory focus (promotion 
focus or prevention focus). The following section summarizes research related to these three components of relationship maintenance, from which hypotheses are generated about the communication, perceptions, and behavior of individuals as a function of both their regulatory focus (promotion focus versus prevention focus) and relationship type (GCR or LDR).

\section{Relationship communication: the impact of computer-mediated}

communication. Often is heard the proverb, "distance makes the heart grow fonder"; in opposition, and still frequently heard is, "out of sight, out of mind". These adages have long existed to support, or condemn, the quality and satisfaction of long-distance relationships (LDRs). There is a certain cultural ideology in place that suggests that romantic couples must be in geographical proximity in order to maintain relationship satisfaction (Helgeson, 1994; Sahlstein, 2004). Many believe that in order for two people to connect on an intimate level of reciprocal and shared meaning, they must be within proximal distance of each other (Duck \& Pittman, 1994). Indeed, lack of proximity and face-to-face communication is reported to be the primary reason for frustration among individuals in a LDR (Rohlfing, 1995; Stafford \& Merolla, 2007).

In a study conducted on communication channels in LDRs, Dainton and Aylor (2002) found that relationship satisfaction was positively correlated with the quantity of face-to-face communication that couples engaged in; the LDR couples with minimal face-to-face communication reported less relationship satisfaction, commitment, and trust for their partner compared to the LDR couples with more frequent face-to-face communication. For couples in a LDR, this dearth of face-to-face communication can contribute to the inability to display nonverbal affection, engage in joint tasks, and be 
involved in the overall daily routine of each other, all of which are primary components of relationship maintenance in geographically-close relationships (Guerrero et al., 2013).

Despite the lack of face-to-face communication in LDRs, many such relationships have still been able to survive and thrive, especially in more recent years (Billedo, Kerkhof, \& Finkenauer, 2015; Merolla, 2012). Guldner (2003) stated that this growing feasibility of long-distance relationships is most likely due to technological increases in computer-mediated communication (CMC), which can serve as a direct and immediate link between partners who are too far away from each other to have frequent face-to-face communication. CMC is broadly defined as any "text, audio, and video exchanges that occur between two or more people with the aid of a computer software interface, including but not limited to private e-mail exchange, private chat rooms, news groups, and the World Wide Web" (Cemalcilar, 2008; p. 365). CMC can serve as a pathway to increased self-disclosure in relationships (Jiang, Bazarova, \& Hancock, 2013); additionally, self-disclosure of more intimate topics is often preferred via CMC compared to face-to-face communication (Walther, 1996), because any mode that is text-based allows the user more time to reflect upon what he or she has written and self-regulate his or her initial thoughts that could otherwise unintentionally slip out during face-to-face communication.

CMC is common among both GCRs and LDRs, with neither relationship type utilizing a greater degree of CMC quantity than the other (Kirkpatrick, 2007). However, $\mathrm{CMC}$ can be more beneficial for individuals in a LDR because of the nature and context of $\mathrm{CMC}$ in these types of relationships. Upon comparing the context of CMC between individuals in a GCR and individuals in a LDR, Kirkpatrick (2007) found that those in a 
GCR most often used CMC to discuss more trivial aspects of their lives, such as errands, responsibilities, and times they would meet up so that they could discuss more intimate topics face-to-face; in contrast, those in an LDR were found to have more intimate interactions over CMC, presumably because they did not have the luxury or convenience to discuss such intimate topics face-to-face. In sum, though the CMC in both relationship types are comparable in quantity, LDRs often have more private and emotionally charged conversations through $\mathrm{CMC}$, which often makes the intimacy of such communication greater compared to that of GCRs (Dainton \& Aylor, 2002; Jiang \& Hancock, 2013).

Indeed, individuals in LDRs report having more intimate communication than those in GCRs (Kelmer, Rhoades, Stanley, \& Markman, 2013; Stafford \& Reske, 1990), in addition to reports of being more in love with their partner (Stafford \& Merolla, 2007; Stafford \& Reske, 1990) and being more dedicated to the relationship (Kelmer et al., 2013). In some instances, relationship satisfaction has been found to be greater among LDRs, as compared to GCRs (Guldner \& Swensen, 1995; Stafford \& Merolla, 2007). Many researchers predict that these enhanced states in LDRs are due to the increased likelihood for idealization in such relationships (Guerrero et al., 2013; Stafford \& Merolla, 2007; Stafford \& Reske, 1990).

Idealization in romantic relationships refers to the defense mechanism in which an individual exaggerates the positive qualities held by a romantic partner (or one's self), while also choosing to not acknowledge their partner's (or self's) less-than-desirable traits (Murray \& Holmes, 1997). Stafford and Merolla (2007) argue that CMC may serve an important role in the idealization process for both GCRs and LDRs; they explained that those in GCRs do not have a large degree of flexibility in their communication, as 
they are routinely face-to-face, allowing far fewer opportunities to plan how they will present themselves to their partner. In contrast, individuals in LDRs have the frequent ability to choose when and where they answer text messages, cell phone calls, and other forms of mediated communication. This level of control over communication (which is uncommon in GCRs) allows individuals in a LDR to present their ideal self in the majority of the communications with their partner. Though these idealized presentations and control over communicative efforts can lead to unrealistic expectations of both one's partner and the relationship (Stafford \& Merolla, 2007), they have been found to be positively associated with relationship commitment, stability, and duration (Stafford \& Reske, 1990). In this case, absence does, in fact, make the heart grow fonder.

Relationship perceptions: the ideal standards model. In order to hypothesize about the differences in perceptions between those in a GCR and those in a LDR, I first present a general model of relationship cognition that conceptualizes the perceptions that people hold in their relationships - the ideal standards model (Simpson et al, 2001). Like regulatory focus theory, the ideal standards model is based on self-discrepancy theory (Higgins, 1987), such that both self and partner perceptions are necessary to understand the behavior that can accrue in response to perceptual discrepancies. However, Simpson et al. (2001) believed that a third component was necessary for conceptualizing the perceptions held between romantic partners - the relationship. These three components (the self, the partner, and the relationship) interlock with one another to form a general model of relationship cognition (see Figure 1), of which elements of the ideal self, the ideal partner, and the ideal relationship all function together to form the interworking ideal standards model. 


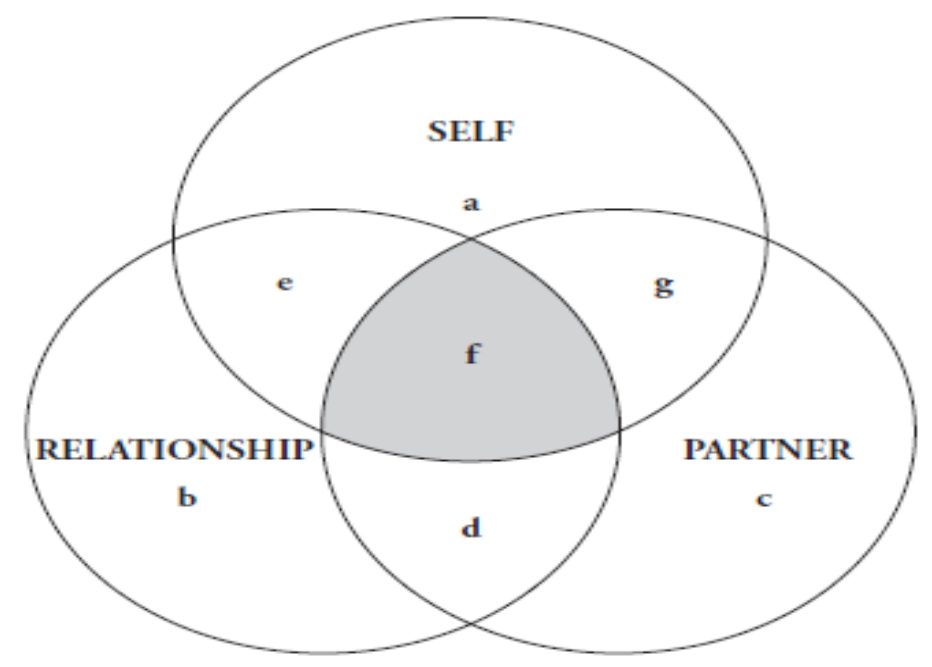

Figure 1. General model of relationship cognition (taken from Fletcher et al., 1999)

In this general model of relationship cognition, the motivations, expectations, goals, and beliefs about ideals exist in the dyadic intersections of the self, one's ideals for a romantic partner, and the thoughts that are held about what makes an ideal relationship (sectors d, e, and g). These concentric overlaps in the differential ideals that are held (sectors a, b, and c) exist because each individual component has an integral function with another to comprise the perceptions about an ideal romance that most people seek. For instance, if an individual (sector a) is someone who perceives him or herself as being very giving and compassionate, he or she will likely hold high ideals for a partner (sector c) who is also giving and compassionate (Fletcher et al., 1999). Perceiving the same ideals that one holds of his or her self in a partner creates congruence between self and partner ideals (sector g), which is referred to as ideal-perception consistency (IPC;

Campbell, Simpson, Kashy, \& Fletcher, 2001).The combined ideal preferences of each of these dyadic intersections, then, represent the ideal standards that one holds in a romantic relationship (sector f). These ideals also entail aspects of Higgins' (1987) “ought self”, 
such as duties, obligations, and expectations, which Simpson et al. (2001) describe as being relational to ideal standards in nature.

The ideal standards model also departs from self-discrepancy theory in regard to the functions that both relationship and partner ideals should enact. In Higgins' (1987) original conceptualization of self-discrepancy theory, he postulated two functions that are engaged in during the process of examining ideals: evaluation and regulation. Simply put, an individual evaluates his or her partner or the existing relationship; if the perception is discrepant from the individual's ideals, regulatory behavior (i.e., attempts to change qualities of one's self or one's partner) often occurs. The ideal standards model, however, proposes that there is a third, mediating function that is enacted - explanation (Simpson et al., 2001). When an individual first perceives his or her partner or relationship as being ideal-discrepant, he or she begins a process of explanation. Often, causal explanations are given as to why the perceived discrepancy exists or past conflicts that may have forecasted the current incongruence. The occasional discrepancy is often overlooked. However, persistent, strong, and prevalent discrepancies that occur over a significant period of time are more difficult to pass off as acceptable behavior (Rusbult, Kumashiro, Stocker, \& Wolf, 2005). It is at this point during which individuals often engage in regulatory attempts, sculpting their self, partner, or relationship through mental representations of the perceived ideals that they hold.

No previous research has examined how perceptions of ideal standards in one's relationship may vary as a function of relationship type (GCR vs. LDR). However, further research on idealization can aid in conceptualizing the ideal-perception consistency (IPC) that individuals in these two types of relationships may hold. Through 
analyzing surveys completed by both geographically-close and long-distance couples, Stafford and Merolla (2007) found that both self-idealization and partner-idealization are more common in LDRs than in GCRs. Stafford and Merolla suggested that selfidealization, in which individuals perceive themselves as being congruent with the ideals that they believe their partner holds, and partner-idealization, in which individuals perceive their partners as being congruent with the ideals that they themselves hold, may serve as defense mechanisms for those in a LDR. That is, perceiving one's self and one's partner as being in congruence with each other's ideals (i.e., holding high self- and partner-IPC) helps individuals cope with relational uncertainty, which is increasingly common in LDRs (Maguire \& Kinney, 2010; Merolla, 2012; Pistole, 2010). Thus, I argue that those in a LDR would likely hold higher self- and partner-IPC than those in a GCR.

Relationship behavior: the role of the self and the partner. Regulation, or behavioral attempts to change the self, partner, or relationship, occur in response to some sort of perceived discrepancy between the actual and the ideal. This discrepancy drives individuals into regulatory behavior to decrease their perceived incongruence from a preexisting standard of behavior. However, this process becomes more complicated in dyadic relationships, such as romantic relationships, because one must consider the role of a partner. In romantic relationships, the discrepancies created can drive individuals into self-regulatory or partner-regulatory behavior. The outcomes that occur from both of these regulatory processes can be positive or negative.

Indeed, romantic partners can be helpful in times of perceived self-discrepancies and can have a unique ability to initiate and motivate behavioral regulation in one's self. Shah (2003) found that when individuals were asked to merely think about close others, 
their motivation for embodying socially desirable traits and commitment to prevailing in tasks that were important to their close others significantly increased. When individuals perceive those in their social proximity as directly aiding them in their goal pursuit, successful behavioral regulation is likely to occur. For example, if Lynette knows Jason is trying to embrace a healthier lifestyle and buys him a new pair of running shoes, then Jason would be more likely to begin an exercise regimen. Indeed, this "goal-relevant social support" has been found to have varying benefits for an individual's lifestyle, including enhanced health maintenance, more positive diet regulation, and increased sleep (Fitzsimons \& Finkel, 2010). In sum, if one is engaging in self-regulatory behavior and has a romantic partner who is supportive and encouraging, then he or she is more likely to be successful in his or her individual goal pursuits, yielding more positive feelings about the self (Overall, Fletcher, \& Simpson, 2010).

Self-regulation in a romantic relationship does not always have such positive outcomes, however. Concerning the potential negative outcomes of self-regulation, problems can occur if individuals modify their behavior to be congruent with the ideals their partner hold for them. In a process called the Michelangelo phenomenon (Rusbult et al., 2005), individuals attempt to change their partner in ways that affirm the ideals they hold for a romantic partner - this process often enacts self-regulatory behavior of the target individual. Consider again Lynette, who believes a healthy lifestyle is important and, because of this, bought Jason a pair of running shoes so that he, too, can hold the ideals that are important to Lynette. Though this scenario may seem in good will, Rusbult and her colleagues (2005) noted that the Michelangelo phenomenon can backfire if the target individual is unable to meet the ideals he or she believes that his or her partner 
hold, which often causes an enhanced awareness of the self-discrepancy from a partner's ideals. If Jason is unable to continue working out because of health reasons, he may begin to notice that his actual qualities do not (and cannot) match Lynette's ideals. There is cause for concern when the discrepant view of the self becomes too large to ignore or readily dismiss. In a survey study, Overall, Fletcher, and Simpson (2006) found that the more self-discrepancies from a romantic partner's ideal that individuals perceived, the more self-regulatory behavior they enacted and the less satisfied they were with their relationship.

As with self-regulation, partner-regulation --- or attempting to change the present qualities of one's partner --- can be done effectively or ineffectively. Positive outcomes of partner-regulatory behavior are often due to the process of accommodation. Accommodation is the ability for individuals to resist their gut instincts to overpower their romantic partner in their regulatory attempts and, instead, transform their attempts to decrease the discrepancies they perceive in their partner into a style that is more constructive (Rusbult, Verette, Whitney, Slovik, \& Lipkus, 1991). Successful accommodation practices, then, involve individuals calmly voicing the concerns they hold of their partner in a way that takes their partner's perspective into consideration. For example, Lynette may refrain from telling Jason that he is eating too much at dinner, even if she knows he is trying hard to have a healthy diet. Instead of initially telling Jason what he should and should not eat, Lynette may instead ask how he has been doing with his diet, thus leading him to think about his own goals. Couples who can engage in successful accommodation practices promote general feelings of acceptance, intimacy, trust, and commitment (Overall \& Sibley, 2008). Such accommodation attempts can 
decrease the discrepancies originally perceived by one's partner, but only if these accommodation techniques are successful.

Unsuccessful accommodation techniques can elicit negative consequences in the relationship. Overall et al. (2006), through analysis of survey reports, found that if individuals were unsuccessful in their accommodation attempts with their partner, they reported an enhanced awareness of the partner discrepancies that existed and were more motivated to engage in increased regulatory efforts. Overall and Simpson (2013) note that increased attempts of unsuccessful partner regulation often result in the target individual feeling less accepted, valued, and appreciated. These regulation attempts can even go to the extent of making the target individual feel as if he or she is trying to be controlled to enhance the personal goal pursuits of his or her partner (Fitzsimons \& Finkel, 2010). For example, consider that Jason does not like that Lynette spends many late nights at work because he is left with the majority of the household responsibilities. If, over time and after many disagreements, Lynette may begin to feel as if Jason does not appreciate the hard work she does to support their family; further, she may feel as if the only reason Jason wants her home earlier is to make his life easier. This process demonstrates how a significant other's behavior can decrease an individual's motivation to engage in accommodation processes, but can also create a certain dilemma for individuals who are dissatisfied with their romantic partner. Dissatisfied partners could refrain from partnerregulatory processes in attempts to maintain longer-term relationship satisfaction and reduce interpersonal conflict (a prevention-focused tactic), or they could engage in more frequent attempts of partner regulation in hopes of some action or change from their partner (a promotion-focused tactic). 
The aforementioned research describes how self- and partner-regulatory processes impact intimate relationships; however, when considering these processes in the context of a LDR, other considerations should be made. For instance, in their review of idealization processes in romantic relationships, Guerrero et al. (2013) suggested that dates and time spent together in a LDR would naturally be planned ahead of time because of both partners wanting to make the most out of what little time they have with each other; these plans not only include what the romantic pair will do with their time together, but also how they will behave toward each other. Indeed, when couples in LDRs are able to spend face-to-face time with each other, they are on their best relational behavior (Guerrero et al., 2013), a process that engages both idealized behavior and self-regulatory skills. In his theoretical explanation of the processes of human bonding, Bochner (1984) stated that displaying one's best behavior (i.e., high self-regulation, low partnerregulation) becomes increasingly difficult in day-to-day interactions, over time; in contrast, LDR couples may lack the consistent interaction needed to dissipate this idealized behavior. Thus, GCR couples should engage in less self-regulatory behavior and more partner-regulatory behavior than LDR couples.

In conclusion of this review of the literature, regulatory focus (promotion focus vs. prevention focus) can impact many of the individual and dyadic motivations that an individual is faced with in his or her life. These motivations, in turn, can aid in predicting how an individual engages in relationship maintenance processes (i.e., communication, perceptions, and behavior). It is important to now take this understanding of regulatory focus, in addition to the behavioral motivations that accompany each orientation, and 
apply them to further understanding the relationship maintenance practices that each type of relationship (GCR vs. LDR) may differentially employ.

\section{The Current Research}

As previously stated, with the growing number of long-distance relationships, there is a need for more research to be conducted on whether the various facets that are currently understood within the context of GCRs can be applied to relationships that are less proximal in nature (i.e., LDRs). The current study first seeks to compare the communication (quantity and intimacy), perceptions (ideal standards), and behavior (self and partner-regulation) between relationship types (GCR vs. LDR); second, it is of interest to explore how individuals' degree of promotion and prevention orientations are associated with these maintenance process and how these associations may differ between relationship types. The results will yield fruitful information for researchers who examine regulatory processes within the romantic relationship context. In addition, individuals in both GCRs and LDRs may utilize these potential findings to better understand themselves, their romantic partners, and their relationships.

\section{Hypotheses on Relationship Communication.}

The first set of hypotheses of this study are in regards to the relationships of both the quantity and intimacy of CMC with one's relationship type. Specifically, the findings of Kirkpatrick (2007) and Dainton and Aylor (2002) on the quantity and intimacy of CMC in GCRs and LDRs are predicted to generalize to the current study. That is, there should be no difference in the quantity of CMC between those in a GCR and those in a LDR; however, individuals in a LDR should rate the intimacy of their CMC higher than individuals in a GCR because of the limited opportunities to discuss intimate topics face- 
to-face when at a distance. Because little, if anything, is known about how each regulatory foci (promotion vs. prevention) may differentially impact the communication that exists in a relationship, no specific hypotheses have been formed in regards to the association of regulatory focus with quantity and intimacy of $\mathrm{CMC}$, though analyses will be conducted to test such a relationship.

H1A. The quantity of CMC will not vary as a function of relationship type.

H1B. The intimacy of CMC, defined as the average degree of emotionally close and private communication maintained through modes other than face-to-face, employed by those in a LDR will be greater than that of those in a GCR, regardless of regulatory focus.

RQ1. Can one's degree of promotion or prevention focus successfully predict CMC quantity or CMC intimacy?

\section{Hypotheses on Relationship Perceptions.}

The second set of hypotheses of this study are that participants' perceptions of their partner and of themselves, in relation to the ideals they hold, will differ as a function of both relationship type (GCR vs. LDR) and individuals' degree of promotion and prevention orientations. As previously mentioned, individuals in a LDR are more likely to engage in both self and partner idealization than individuals in a GCR; indeed, individuals in a LDR often make their idea of an ideal partner to be in congruence with their partner perceptions, in addition to perceiving their own self as being in congruence with the ideals held by their partner (Guerrero et al., 2013); thus, individuals in a LDR should have a higher ideal-perception consistency (IPC) of both themselves and their partner. 
Little, if any, research has been conducted to examine how individuals' regulatory focus may serve as a function of the IPC they hold for both themselves and their partners. As previously summarized, however, Lackenbauer and Campbell (2012) found that individuals who were asked to think of ways in which their partner was discrepant from their ideals (partner-IPC) embraced promotion-focused tactics of emotion regulation to a greater degree than individuals assigned to the self-discrepancy prime. In contrast, individuals asked to think of ways in which they themselves were discrepant from the ideals held by their partner (self-IPC) embraced prevention-focused tactics of emotion regulation to a greater degree than individuals assigned to the partner-discrepancy prime. The same associations between (a) partner-discrepancy and promotion focus and (b) selfdiscrepancy and prevention focus are expected in the current study. Specifically, I will be using IPC in order to examine if one perceives him or herself as congruent with his or her partner's ideals (self-IPC) and if one perceives his or her partner as congruent with his or her own ideals (partner-IPC).

H2A. Individuals in a LDR will report higher self-IPC and partner-IPC than will individuals in a GCR, regardless of regulatory focus; that is, those in a LDR will be more likely than those in a GCR to perceive themselves as being congruent with their partner's ideals and more likely to perceive their partner as being congruent with their own ideals.

H2B. There will be a negative association between degree of promotion focus and partner-IPC; that is, increased levels of promotion focus will be associated with less perceived partner-congruence to one's ideals, regardless of relationship type. 
$\mathrm{H} 2 \mathrm{C}$. There will be a negative association between degree of prevention focus and self-IPC; that is, increased levels of prevention focus will be associated with less perceived self-congruence to a partner's ideals, regardless of relationship type.

\section{Hypotheses on Relationship Behavior.}

The final set of hypotheses of this study focus on how self- and partner-regulatory behavior --- measured by the frequency of attempts to change qualities of one's self and one's partner respectively --- vary as a function of relationship type (GCR vs. LDR) and individuals' degree of promotion and prevention orientations. As noted, individuals in a LDR are often on their best relational behavior when they have the opportunity to spend face-to-face time with their romantic partner, likely because they want their limited time together to not be spent fighting about problems that may exist in their relationship(Guerrero et al., 2013). Because individuals in a GCR spend significantly more time with their partner, in addition to the increased difficulties of maintaining an image of an ideal partner over time (Bochner, 1984), they should engage in less selfregulatory behavior and more partner-regulatory behavior than individuals in a LDR.

Promotion-focused individuals have been found to confront relationship problems head-on because of their primary concern with relationship growth (Winterheld \& Simpson, 2011). Additionally, they can become overly focused on obtaining gratifying outcomes, and often hope and ask for more out of their romantic partner than they can feasibly provide (Winterheld \& Simpson, 2011). From this, I predict that individuals who are highly promotion-focused in their regulatory orientation will enact more partnerregulatory behavior than those with lower promotion-focused orientations. In contrast, prevention-focused individuals tend to avoid relationship problems because of their 
primary concern with relationship security (Higgins, 1997). Additionally, they can become overly focused on preventing relationship difficulties (Higgins, 1997), which could result from partner-regulatory attempts. As such, it could be expected that they would enact more self-regulatory behavior. Hence, I predict that individuals who are highly prevention-focused in their regulatory orientation, compared to those with lower prevention-focused orientations, will enact more self-regulatory behavior in attempts to keep their partner satisfied. From this information, the following hypotheses are proposed:

H3A. Individuals in a LDR will engage in self-regulation to a greater degree than individuals in a GCR, regardless of regulatory focus. In contrast, individuals in a GCR will engage in partner-regulation to a greater degree than individuals in a LDR, regardless of regulatory focus.

H3B. There will be a positive association between degree of promotion focus and partner-regulation; that is, increased levels of promotion focus will be associated with more attempts to change qualities in one's partner, regardless of relationship type.

H3C. There will be a positive association between degree of prevention focus and self-regulation; that is, increased levels of prevention focus will be associated with more attempts to change qualities in one's self, regardless of relationship type. 


\section{CHAPTER II}

\section{STUDY DESIGN}

\section{Participants}

Individuals in a geographically-close relationship (GCR) or a long-distance relationship (LDR) were recruited from three online samples: (1) Amazon.com's Mechanical Turk (MTurk; an online site that recruits willing individuals to partake in qualifying microtasks and surveys in exchange for financial compensation, Aguinis \& Lawal, 2013); (2) a Midwestern university’s psychology participant pool; and (3) the Social Psychology Network (SSN). Participants recruited through MTurk received $\$ 0.50$ for their time, while participants recruited through the psychology participant pool received extra credit applied to one of their psychology-related courses; those recruited through the SSN participated without compensation.

All participants were required to be in a romantic dating relationship and could not be engaged or married; past research has found that married individuals use different maintenance strategies than do dating individuals (Dainton \& Sanford, 1993) ${ }^{1}$. In addition to this stipulation, participants were required to be at least 18 years of age and to have been in their current relationship for at least three months (as idealization is most common in the beginning stages [i.e., first few months] of a relationship, Guerrero et al., 2013). 
Of the recruited sample of 256 participants who completed the survey in full (58 participants opened the survey, but did not complete it), 71 were omitted before data analysis for the following reasons: 31 for taking five minutes or less to complete the survey, 25 for not passing two out of the three quality check questions that were placed throughout the survey (e.g., "I frequently go scuba diving in hot lava" [1 = completely disagree, 7 = completely agree), 9 individuals in LDRs who were currently visiting their partners $^{2}, 6$ that were detected as multivariate outliers ${ }^{3}$, and 5 individuals in LDRs who reported to have never seen their partner face-to-face. Of the final sample of 180 participants $(M$ age $=26.66), 90$ were from MTurk $(50 \%), 72$ were from the psychology participant pool (40\%), and 18 were from the Social Psychology Network (10\%). Eighty participants classified themselves as being in a LDR, with the average miles away from their partner's home residence being 1034.40 (ranging from 33 - 110000 miles). One hundred participants classified themselves as being in a GCR, with the average miles from their partner's home residence being 8.00 (ranging from $0-80$ miles). Further demographic information is provided in Table 1. 


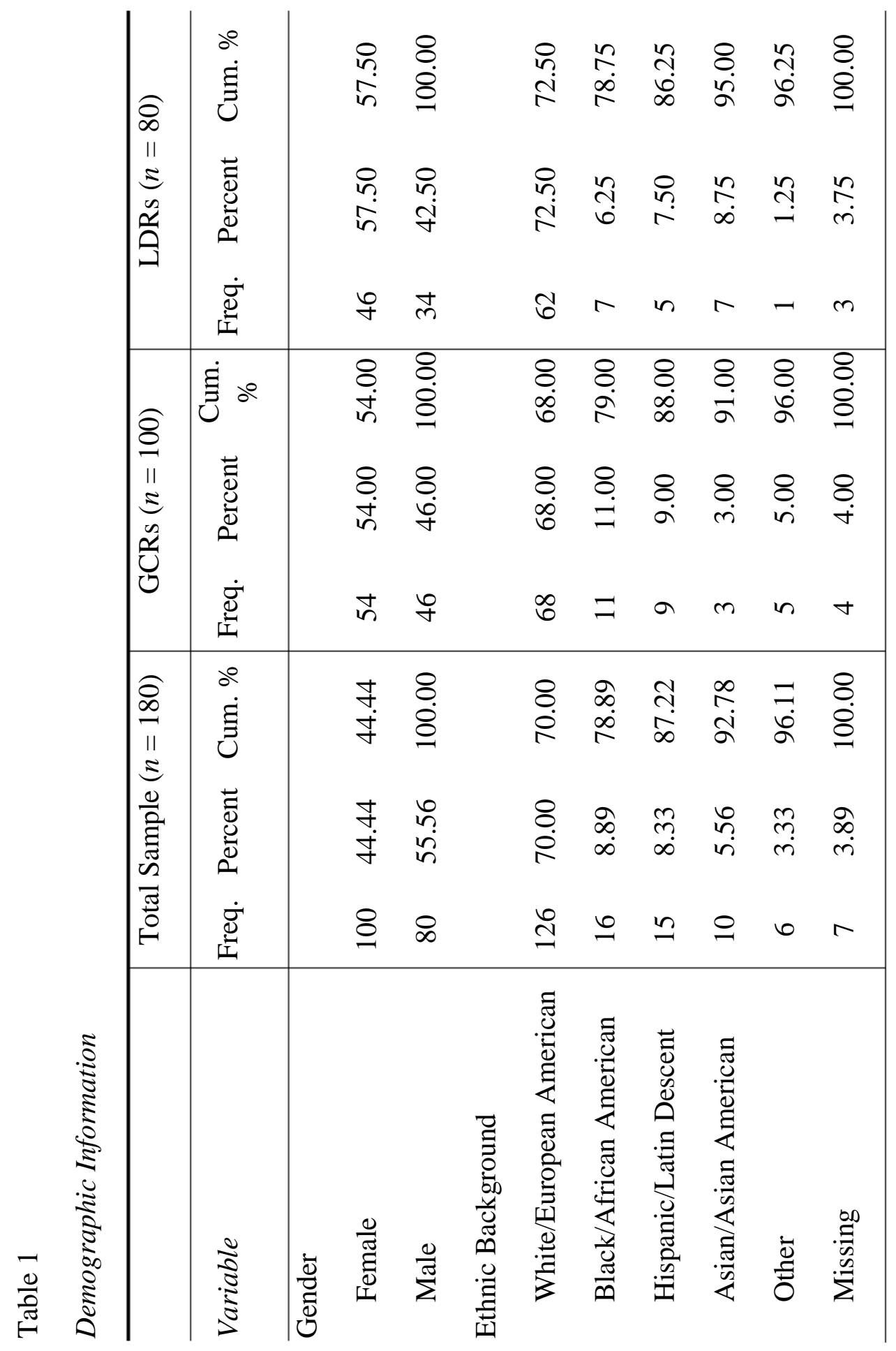




\section{Measures}

\section{Demographics}

General demographic information was collected, including gender, age, race, and sexual orientation. Characteristics of the participants' relationships were also collected, including how far they lived away from their partner (in miles), the last time they saw their partner face-to-face $(1=$ I have never seen my partner face-to-face, $7=$ today $)$, and the type of relationship they were currently in (GCR or LDR). Defining what characterizes a LDR has been met with many different approaches in past research. Researchers have categorized relationships as long-distance by using metrics of distance between each partner's city of primary dwelling (Helgeson, 1994), how long it takes to travel to meet one's partner face-to-face (Know, Zusman, Daniel, \& Barantley, 2002), and the number of nights partners spend with each other on an average week (Holmes, 2004). Stafford (2005) proposes that LDRs "defy precise definitions" (p. 7), which is evident through the aforementioned categorization preferences. However, the most frequent technique that researchers use to categorize individuals by relationship type is by simply asking individuals if they consider their relationship to be long-distance (Glunder

\& Swensen, 1996; Stafford \& Merolla, 2007; Van Horn et al., 1997). For the purposes of the current study, relationship type was assessed by answering "yes" or "no" to the question, "are you currently in what you would consider a long-distance relationship?" Analyses of the frequencies of distance from one's partner (in miles) confirmed that participants' self-categorizations as reasonable. The shortest distance reported for an individual in a LDR was 33 miles, with the longest distance reported for an individual in a GCR being 80 miles. 


\section{Regulatory Focus}

Degree of promotion and prevention focus was assessed using 14 questions from the Regulatory Focus in Relationships Scale (Winterheld \& Simpson, 2011; see Appendix B). This scale taps into promotion and prevention concerns that are specifically related to romantic relationships. Examples of the eight promotion items used included, "I often think about how I can achieve (or create) a successful relationship", "Overall, I want to feel inspired and uplifted in my relationships", and "Overall, I am more oriented toward creating positive outcomes than preventing negative outcomes in my relationship." Examples of the six prevention items used included, "I am often anxious that I am falling short of my duties and obligations in my relationships", "I often worry that I will fail to accomplish my relationship goals", and "Overall, I am more oriented toward preventing negative outcomes in my relationship that I am toward achieving positive outcomes". ${ }^{4}$ All items were rated on a 7-point scale $(1=$ highly disagree, $7=$ highly agree). Items related to each regulatory orientation, respectively, were averaged in order to assess overall promotion focus and overall prevention focus in relationships. Higher scores reflect an increased likelihood to embrace that particular focus in times that call for maintenance behaviors in romantic relationships (promotion $\alpha=.79$; prevention $\alpha$ $=.79)$.

\section{Relationship Communication}

Two measures of relationship communication were completed by participants CMC quantity and CMC intimacy.

CMC quantity. To assess relationship communication quantity, participants were presented with a list of common modes of computer-mediated communication in a 
relationship and were then asked to report how often they engaged in each communication mode with their partner on a 7 -point scale $(1=$ never, $7=$ every day $)$. These included: (a) phone calls, (b) texting, (c) video chat, (d) social media messaging (i.e., Facebook, Snapchat, and Twitter) and (e) email. Participants' scores of $C M C$ quantity on all potential modes were averaged, with higher scores reflecting a greater degree of CMC utilized in the relationship. ${ }^{6}$

CMC intimacy. To assess relationship communication intimacy, participants were presented the same list of communication modes that were used to assess $C M C$ quantity, but were then asked to report how intimate (i.e., emotionally close, private) the conversation is (in a typical week) when using each communication mode on a 8-point scale $(0=$ not intimate at all or we never use this communication mode, $7=$ extremely intimate). Participants' scores of CMC intimacy on the modes they reported utilizing (i.e., not including ' 0 ' scores) were averaged, with higher scores reflecting a greater degree of intimacy in communication.

\section{Relationship Perceptions}

The short version of the Partner Ideal Scale (Fletcher et al., 1999) was used to examine the perceptions that participants had of ideal standards in their romantic relationship. This scale has produced good test-retest reliability, internal reliability, and predictive and convergent validity when used to test for the importance of ideal standards in one's relationship (Campbell et al., 2001; Fletcher et al., 1999; Fletcher \& Thomas, 2000; Overall et al., 2006). Seventeen items from the scale were used to create three different relationship ideal dimensions: warmth/trustworthiness ("kind", "supportive", "good listener", "considerate", "sensitive", and "supportive"), attractiveness/vitality 
("good lover", "attractive appearance", "outgoing", "nice body", "adventurous", and "sexy"), and status/resources ("financially secure", "good job", "dresses well”, "nice house", and "successful"). Replicating Overall et al. (2006), the phrase, "or potential to achieve", was added after each of the status/resources items (e.g., nice house [or potential to achieve]). Confirmatory factor analysis verified the factorial structure of the three relationship ideal dimensions, $x^{2}(136)=1330.05, p<.001$. Average scores from the 17 ideals were used to create the subscales of partner-IPC and self-IPC.

Partner-IPC. First, participants were asked to rate each item in terms of what they believed was important in conceptualizing an ideal partner in a romantic relationship $(0=$ very unimportant, $6=$ very important $)$. Then, participants were asked to rate each item in terms of how accurately it described their current partner in relation to their own ideals that they had just stated $(1=$ does not match my ideal at all, $7=$ completely matches my ideal). Participants' scores of partner-IPC on all 17 ideal characteristics were averaged, with higher scores reflecting individuals perceiving their partner's actual qualities as being consistent with the ideal qualities these individuals hold for their partner $(\alpha=.92)$.

Self-IPC. First, participants were asked to rate each item in terms of what they believed was important to their partner in conceptualizing an ideal partner in a romantic relationship $(1=$ very unimportant, $7=$ very important $)$. Then participants were asked to rate each item in terms of how accurately it described their own self in relation to their partner's ideals that they had just stated $(1=$ does not match my partner's ideal at all, $7=$ completely matches my partner's ideal). Participants' scores of self-IPC on all 17 ideal characteristics were averaged, with higher scores reflecting individuals perceiving their 
self's actual qualities as being consistent with the ideal qualities their partners hold for them $(\alpha=.92)$.

\section{Relationship Behavior}

The same short version of the Partner Ideal Scale (Fletcher et al., 1999) that was used to measure relationship perceptions was also used to measure the relationship behavior that participants enacted in their relationships. Average scores from the 17 ideals were used to create the subscales of partner-regulation and self-regulation.

Partner-regulation. Participants were asked to rate each item in terms of how often they had attempted to change that aspect of their current partner in the past 6 months $(1=$ not tried at all to change, $7=$ tried hard to change $)$. Participants' scores of partner-regulation on all 17 ideal characteristics were averaged, with higher scores reflecting a greater degree of partner-regulation $(\alpha=.93)$.

Self-regulation. Participants were asked to rate each item in terms of how often they had attempted to change that aspect of their self in the past 6 months $(1=$ not tried at all to change, $7=$ tried hard to change). Participant' scores of self-regulation on all 17 ideal characteristics were averaged, with higher scores reflecting a greater degree of selfregulation $(\alpha=.95)$.

\section{Quality Checks}

In order to increase the overall validity of participant responses, three "quality check" questions were randomly placed throughout the survey. These questions were included to ensure that all participants were reading and responding to each question carefully, rather than quickly completing the survey. These self-generated questions included: "How often do you have heart attacks while watching television?" $(1=$ never, 7 
= very frequently $)$, "I frequently go scuba diving in hot lava." $(1=$ completely disagree, 7 = completely agree , and "I can hold my breath underwater for longer than 50 minutes" $(1=$ completely disagree, $7=$ completely agree $)$. Data from participants who responded anywhere between 3 and 7 for at least two out of the three questions were excluded from analyses. $^{5}$

\section{Procedure}

A link to the survey was posted on each recruitment channel. Participants recruited via MTurk could find the posting by searching for any of the following keywords: "Romantic Relationships", "Relationships", "Long Distance", "Distance", "Romance", "Love", "Romantic", "Demographics", and "Survey". Participants recruited via the university's SONA system or the SSN could find the posting among all the surveys that were currently available. The posting was titled "Survey for Individuals in a Geographically-Close or Long-Distance Relationship" and included the following description:

"We are collecting survey responses about romantic relationships. Specifically, you will be asked about some of the communication methods you use with your partner, how you and your partner perceive each other, and how you and your partner have changed within the past six months. You must meet the following requirements to participate: be at least 18 years of age; have been in your current romantic relationship for at least 3 months; must NOT be engaged or married. Click on the link below to begin the survey if you meet these qualifications." 
Upon clicking the link to the survey, participants were linked to the online survey. An informed consent form was first presented; after clicking "I agree", participants were directed to the rest of the survey. The measures were completed by participants in the following order: Demographics, Regulatory Focus in Romantic Relationships Scale, CMC Quantity, CMC Intimacy, Partner-IPC, Partner-Regulation, Self-IPC, SelfRegulation. Upon completion of the survey, participants were presented with debriefing information, which also provided the researcher's and advisors' contact information for questions, along with a thank you statement for participation. The compensation ( $\$ .50$ for the MTurk participants and $1 / 2$ point of extra credit for the psychology participant pool participants) was then transferred to the personal accounts of all participants who completed the survey. 


\section{CHAPTER III}

\section{RESULTS}

\section{Preliminary Analyses}

Preliminary analyses of the means and intercorrelations between the key dependent variables of the total sample are displayed in Table 2. Overall, individuals were found to be more promotion-oriented in their romantic relationships than prevention-oriented, $t(179)=14.13, p<.001$. Participants reported a moderate degree of CMC quantity and CMC intimacy (with the two being positively associated) and perceived that, on average, their partners and their selves were highly consistent with each other's ideals $(M$ partner-IPC $=5.66 ; M$ self-IPC $=5.61)$. Individuals were more likely to enact self-regulatory behavior than partner-regulatory behavior, $t(179)=8.35, p$ $=.001$. Unsurprisingly, partner-IPC was negatively correlated with partner-regulation; that is, if one perceived his or her partner's actual qualities as being consistent with the ideal qualities that he or she holds, then behavioral regulation of the partner was not likely. Likewise, self-IPC was negatively correlated with self-regulation; that is, if one perceived his or her actual qualities as being consistent with the ideal qualities that his or her partner holds, then behavioral regulation of the self was not likely. Partner-IPC and self-IPC were strongly correlated in a positive direction, as were partner-regulation and self-regulation. As could be expected, partner-IPC was significantly more strongly associated with partner-regulation $(r=-.38)$ than self-regulation $(r=-.15), t=-3.23, p<$ 
.001. While self-IPC was also more strongly associated with partner-regulation $(r=-.31)$ than self-regulation $(r=-.26)$, the difference between the strengths of the correlation coefficients was not statistically significant, $t=-.69, p=.49$. 


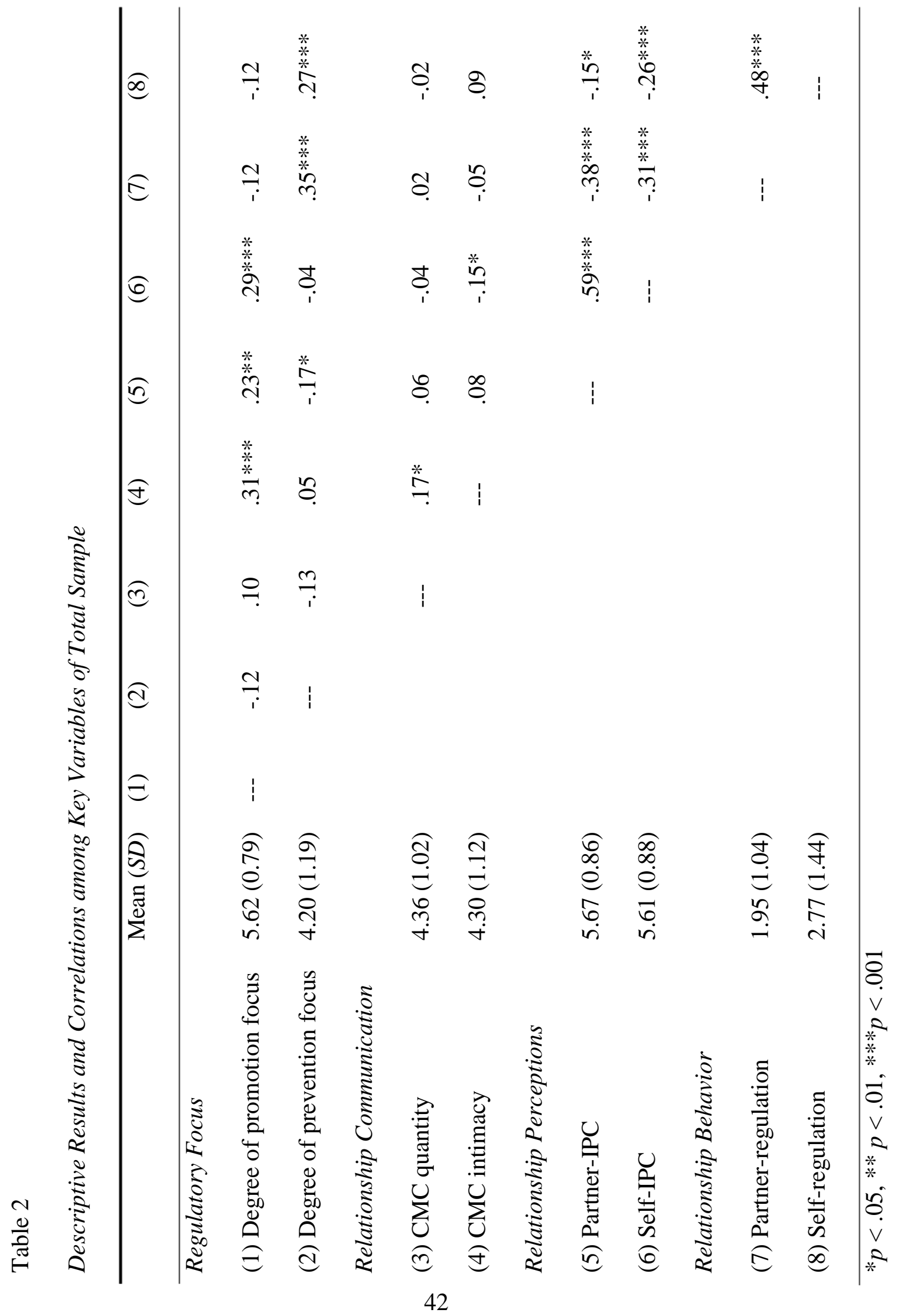


Upon testing for gender differences in relationship maintenance behaviors, no significant differences were found between males and females in their reported CMC intimacy, partner-IPC, or partner-regulation. Males $(M=4.66)$ did report a greater degree of CMC quantity in their relationships than females $(M=4.11), \beta=-.263, t(179)=-$ $3.625, p<.001$. Females $(M=5.79)$, however, perceived themselves as more consistent with their partners' ideal than did males $(M=5.39), \beta=.252, t(179)=3.408, p=.003$. A follow-up MANOVA revealed that this difference was only significant for the warmth/trustworthiness dimension. Females $(M=2.95)$ also reported a marginally greater degree of self-regulation than males $(M=2.54), \beta=.139, t(179)=1.914, p=.057$; this difference was only significant for the attractiveness/vitality dimension.

\section{Primary Analyses}

All hypotheses and research questions were tested using multiple linear regression. Main effects of participants' relationship type (coded +1 for those in a GCR and -1 for those in a LDR) and standardized ratings of their degree of promotion focus and degree of prevention focus were entered into the regression simultaneously. Additionally, terms for the relationship type $\mathrm{x}$ promotion focus and relationship type $\mathrm{x}$ prevention focus interactions were created and entered into the regression in order to explore whether regulatory orientations operate differently between relationship types in predicting maintenance behaviors (i.e., communications, perceptions, behaviors). However, results indicated no relationship type $\mathrm{x}$ promotion focus or relationship type $\mathrm{x}$ prevention focus interactions in predicting any maintenance behaviors; as such, interactions between these variables will not be discussed further. ${ }^{7}$ The following summary of results will focus on each of the maintenance behaviors, individually. No 
effects of participants in LDRs were moderated by the number of miles they lived away from their partner or the last time they reported seeing their partner.

\section{Relationship Communication (Hypothesis 1)}

The aforementioned analysis was conducted on each of the two dependent measures subsuming relationship communication - CMC quantity and CMC intimacy.

CMC quantity. As seen in Figure 2, results indicated a significant main effect of relationship type on the quantity of communication enacted with participants' relationship partners, $\beta=-.301, t(179)=-4.267, p<.001$. Those in a LDR $(M=4.68)$ reported more frequent communication than those in a $\operatorname{GCR}(M=4.10)$. Interestingly, even though a significant amount of variance was explained $\left(\eta^{2}=.16\right)$, univariate comparisons of the $\mathrm{CMC}$ quantity for each of the five modes of CMC were significant only for video chat and social media messaging. Even though the significant difference in CMC quantity may be driven primarily by the above communication mediums, the pattern of mean differences was unusual enough to be detected by a Hoteling $T^{2}$ two independent group analysis, $T^{2}=31.53, F(5,161)=6.15, p<.001$, Mahalanobis $D=$ 0.88. Overall, this leaves Hypothesis 1A unsupported. While there was no main effect of participants' degree of promotion focus in predicting CMC quantity, $\beta=.134, t(179)=$ $1.514, p=.132$, there was a significant main effect of participants' degree of prevention focus, $\beta=-.172, t(179)=-2.399, p=.017$. Those with a high degree of prevention focus $(M=4.24)$ engaged in less frequent communication than did those with a low degree of prevention focus $(M=4.47)$. 


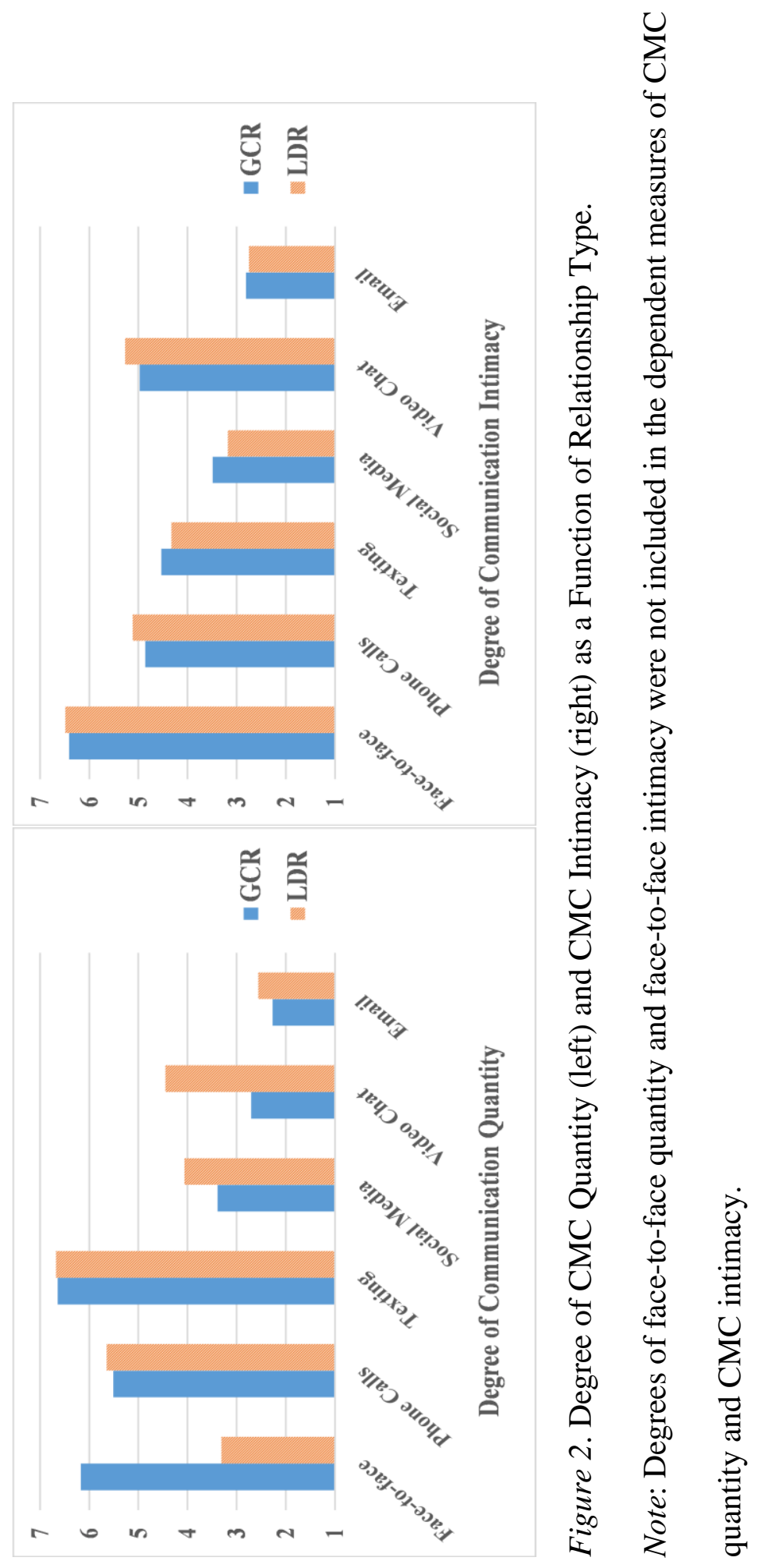


CMC intimacy. In comparing relationship types on the intimacy of communication enacted with participants' relationship partners (see Figure 2), no significant difference was found, $\beta=-.019, t(179)=-.265, p=.791$, lending no support to Hypothesis 1B. Participants' degree of promotion focus, however, did successfully predict CMC intimacy, $\beta=.305, t(179)=4.052, p<.001 ;$ those with a high degree of promotion focus $(M=4.59)$ reported significantly more intimate communication than did those with a low degree of promotion focus $(M=3.96)$. No main effect was found for degree of prevention focus, $\beta=.008, t(179)=.112, p=.911$.

\section{Relationship Perceptions (Hypothesis 2)}

The aforementioned analysis was conducted on each of the two dependent measures subsuming relationship perceptions - partner-IPC and self-IPC.

Partner-IPC. There was no main effect of relationship type on partner-IPC, $\beta=-$ $.005, t(179)=-.068, p=.945$. That is, there was no difference between individuals in GCRs and individuals in LDRs in perceiving their partners as being consistent with their ideal standards. This does not support Hypothesis 2A. There were, however, significant main effects of both degree of promotion focus, $\beta=.235, t(179)=3.135, p=.002$, and degree of prevention focus, $\beta=-.198, t(179)=-2.699, p=.008$ (see Figure 3a). Individuals with a high degree of promotion focus $(M=5.80)$ perceived their partners as more consistent with their ideals than did those with a low degree of promotion focus $(M$ = 5.52), refuting Hypothesis 2B. In turn, individuals with a high degree of prevention focus $(M=5.52)$ perceived their partners as less consistent with their ideals than did those with a low degree of prevention focus $(M=5.82)$. 
Self-IPC. Though at marginal significance, individuals in LDRs $(M=5.73)$ perceived themselves to be more consistent with their partners' ideals than did individuals in GCRs $(M=5.52), \beta=-.127, t(179)=-1.775, p=.078$. This leaves Hypothesis 2A partially supported. Concerning regulatory orientations in predicting selfIPC (see Figure 3b), there was a highly significant main effect of degree of promotion focus, $\beta=.282, t(179)=3.787, p<.001$; participants with a high degree of promotion focus $(M=5.73)$ perceived themselves to be more consistent with their partners' ideals than did participants with a low degree of promotion focus $(M=5.48)$. There was no main effect of degree of prevention focus, $\beta=-.082, t(179)=-1.120, p=.264$, refuting Hypothesis 2C. 


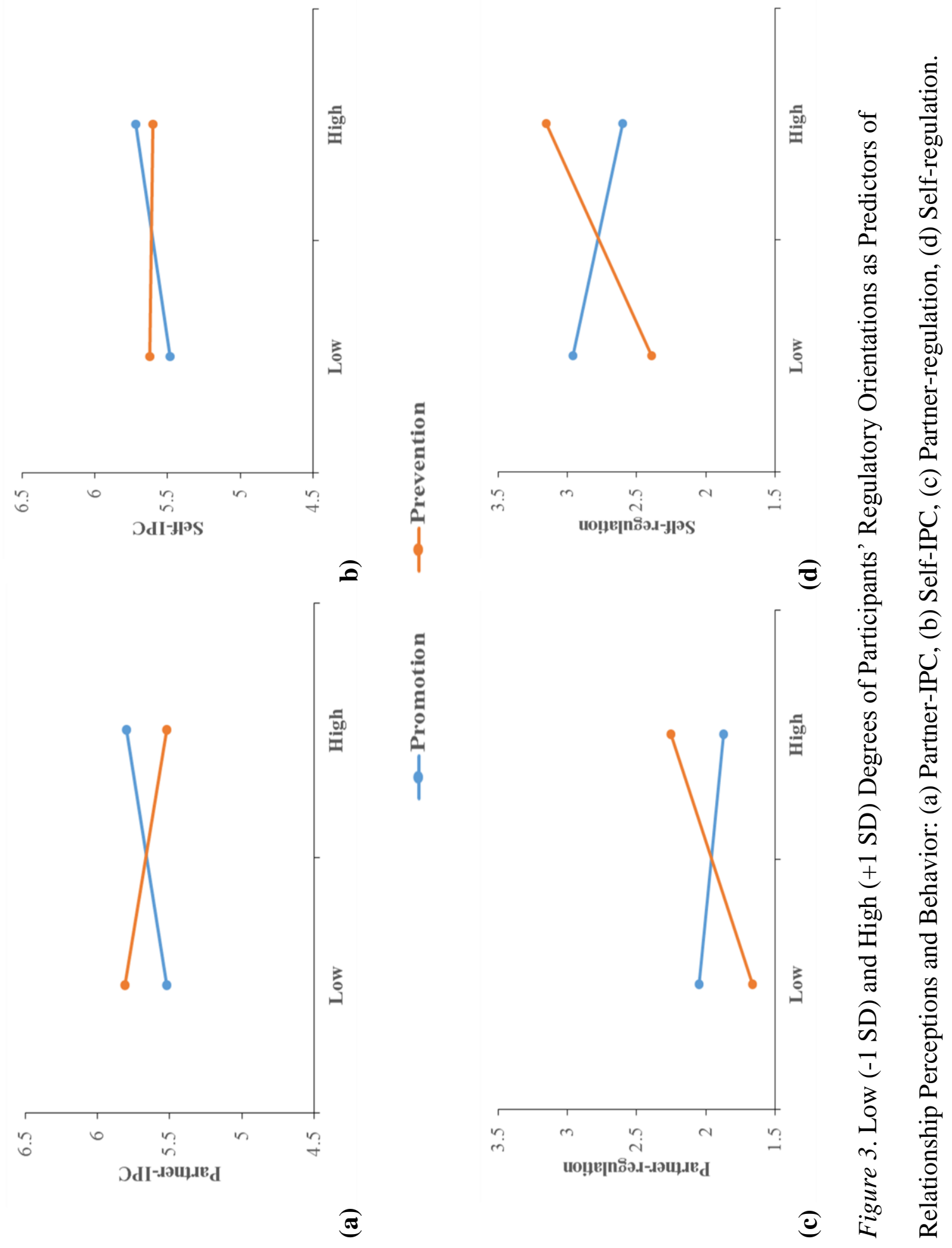




\section{Relationship Behavior (Hypothesis 3)}

The aforementioned analysis was conducted on each of the two dependent measures subsuming relationship behavior - partner-regulation and self-regulation.

Partner-regulation. In comparing relationship types in their degree of partnerregulation, no significant difference was found, $\beta=.053, t(179)=.761, p=.448$; this does not support Hypothesis 3A. There were, however, significant main effects of both degree of promotion focus, $\beta=-.158, t(179)=-2.170, p=.031$, and degree of prevention focus, $\beta=.370, t(179)=5.184, p<.001$ (see Figure $3 c$ ). Individuals with a high degree of promotion focus $(M=1.87)$ engaged in behavioral regulation of their partner less often than individuals with a low degree of promotion focus $(M=2.05)$, contradicting Hypothesis 3B. Though no hypothesis was made regarding the relationship between degree of prevention focus and partner-regulation, individuals with a high degree of prevention focus $(M=2.25)$ engaged in behavioral regulation of their partner more often than individuals with a low degree of prevention focus $(M=1.66)$.

Self-regulation. Though at marginal significance, individuals in GCRs $(M=$ 2.91) engaged in behavioral regulation of their selves more often than individuals in LDRs $(M=2.59), \beta=.131, t(179)=1.827, p=.069$, thus refuting Hypothesis $3 \mathrm{~A}$. In testing for regulatory orientations predicting self-regulation, significant main effects were found for both degree of promotion focus, $\beta=-.154, t(179)=-2.067, p=.040$, and degree of prevention focus, $\beta=.292, t(179)=4.020, p<.001$ (see Figure $3 \mathrm{~d}$ ). Though no hypothesis was made regarding the relationship between degree of promotion focus and self-regulation, participants with a high degree of promotion focus $(M=2.60)$ engaged in behavioral regulation of their selves less often than individuals with a low degree of 
promotion focus $(M=2.96), \beta=-.154, t(179)=-2.067, p=.040$. In turn, individuals with a high degree of prevention focus $(M=3.15)$ engaged in behavioral regulation of their selves significantly more often than individuals with a low degree of prevention focus ( $M$ $=2.39), \beta=.292, t(179)=4.020, p<.001$, supporting Hypothesis $3 \mathrm{C}$. 


\section{CHAPTER IV DISCUSSION}

The objective of the current research was to examine how individuals' degree of promotion and prevention orientations predict multiple facets of relationship maintenance (i.e., communication, perceptions, and behavior), while simultaneously testing these associations as a function of participants' relationship type (GCR vs. LDR). Few differences were found between relationship types, except for in levels of CMC quantity, self-IPC, and self-regulation (with the latter two at marginal significance). Promotion and prevention orientations, however, did appear to differentially predict relationship maintenance processes. Greater degrees of promotion focus were associated with more intimate communication, more ideal-consistent perceptions of one's partners and one's self, and less behavioral regulation of one's partner and one's self. Conversely, greater degrees of prevention focus were associated with less frequent communication, less idealconsistent perceptions of one's partner, and more behavioral regulation of one's partner and one's self.

In the following discussion of results, I will speculate on why hypotheses were largely unsupported or refuted. First, I will describe how the evolving scope of computermediated communication (CMC) could be changing and improving the way in which individuals in LDRs are maintaining their relationships, in addition to the role that regulatory orientations may play in such communication. Next, speculations will be discussed as to why there were no differences between individuals in GCRs and LDRs 
concerning their perceptions of their partners' ideal-perception consistency (i.e., partnerIPC); further, explanations will be given regarding how regulatory orientations differentially function as predictors of partner- and self-IPC. Finally, reasons will be given to why individuals' degree of self-regulation, but not partner-regulation, differs between relationship types. The role that promotion and prevention orientations play in predicting regulatory behavior will also be analyzed.

\section{Relationship Communication: The Evolution of Computer-Mediated Communication}

The role that CMC plays in the maintenance of romantic relationships, regardless of relationship type, is pertinent. Communication technologies afford romantic partners the ability to share their daily experiences and thoughts with each other, whether these be intimate affections or more mundane check-ins. Indeed, the frequency of these shared experiences via $\mathrm{CMC}$ has been found to be positively associated with relationship satisfaction among GCRs (Miller-Ott, Kelly, \& Duran, 2012; Morey, Gentzler, Creasy, Aberhauser, \& Westerman, 2013) and LDRs (Kirk, 2013; Neustaedter \& Greenberg, 2012). Though CMC may elicit positive outcomes in both GCRs and LDRs, the aim of the current research was to compare the quantity and intimacy of CMC between these relationship types.

Based on past research (Kirkpatrick, 2007), it was predicted in the current study that there would be no differences between relationship types in the quantity of CMC enacted in the relationship (Hypothesis 1A), but that those in a LDR would report a greater degree of intimacy in their CMC than those in a GCR (Hypothesis 1B). Neither hypothesis was supported; those in LDRs reported a greater degree of CMC quantity than 
did those GCRs, but there was no difference between the relationship types regarding the intimacy of CMC reported. These results are speculated to be largely due from the rapid evolution of CMC in the past decade, especially among smartphones. Only $2 \%$ of Americans were estimated to own a smartphone in 2005 (comScore, 2008), compared to nearly $80 \%$ today (comScore, 2016).

This rise in accessibility to smartphones has brought with it increased opportunities for long-distance partners to communicate with each other. Surges in mobile applications such as Instagram, Snapchat, in addition to mobile forms of social media sites (e.g., Facebook, Twitter) and video-based communication (e.g., Skype, Facetime, Google Hangouts), have given those in LDRs communicative options like never before. Long-distance partners may be especially motivated to engage in these newer forms of CMC in order to increase their limited repertoire of connections with each other. Geographically-close partners may not be as motivated to engage in such communications because their face-to-face contact already accomplishes many of the benefits that these newer forms of communication bring about (e.g., a shared social presence, implementation of non-verbal language). The post-hoc comparisons conducted support this notion, having revealed that the difference in $\mathrm{CMC}$ quantity between relationship types was primarily driven by video chat and social media messaging.

Though this surge in newer forms of CMC in the past decade can explain why those in LDRs engage in a greater quantity of CMC than those in GCRs, less is clear regarding the null result of CMC intimacy between relationship types in the current study. CMC has played a large role in the formation and maintenance of relationships in the past decade; however, the research regarding such processes is in its beginning stages 
(Stafford \& Hillyer, 2012), with a limited number of published studies having explored such phenomena. Though long-distance partners may have little choice in discussing intimate matters via CMC by virtue of geographical separation, more recent research has found that geographically-close partners are commonly utilizing CMC to express affection to and stay in perpetual contact with each other (Ruppel, 2015; Stewart, Dainton, \& Goodboy, 2014; Toma \& Choi, 2015). Toma and Choi (2015) suggest that this new ability to stay constantly connected with another individual allows geographically-close partners, in particular, to "plan, coordinate, and execute goals effectively, while feeling connected and in synch with each other" (p. 7). This synchrony could foster reports of CMC intimacy for those in GCRs to the level reported by individuals in LDRs, explaining the null result found in the current research.

No past research has explored the role that promotion and prevention foci hold in predicting CMC quantity or CMC intimacy (RQ1). Level of prevention focus, but not promotion focus, was successful in predicting CMC quantity. Specifically, those who held a high degree of prevention focus engaged in less frequent CMC than those who held a low degree of prevention focus. This could be due, in part, to the notion that highly prevention-oriented individuals are more likely to withdrawal from their partner in times of relational uncertainty, compared to individuals who are low in prevention focus (Winterheld \& Simpson, 2011). Additionally, highly prevention-focused individuals could engage in a limited amount of CMC because of their concern with relationship stability; avoiding communication over CMC in times of relationship distress may be one tactic these individuals use in order to prevent discussions that could upset the stability of the relationship. In regard to CMC intimacy, degree of prevention focus was not found as 
a significant predictor. Degree of promotion focus, however, did successfully predict CMC intimacy, such that those who held a high degree of promotion focus reported more intimate CMC than those with a low degree of promotion focus. As stated, highly promotion-focused individuals are focused on fostering relationship growth and enhancing positive emotions in their relationships (Winterheld \& Simpson, 2011). It would make sense, then, for these individuals to enact more affections over communication technology, in turn increasing their sense of CMC intimacy. This begs the question of whether these intimate expressions could foster idealized perceptions of one's partner or one's self.

\section{Relationship Perceptions: Bridging the Gap between Communication and Behavior}

How, when, and to what extent romantic couples communicate can facilitate the way in which individuals perceive themselves and their partners. Ideal perceptions (i.e., warmth/trustworthiness, attractiveness/vitality, status/resources) can be made accurate (or discrepant) from first impressions upon enacting verbal or computer-mediated communication. Further, the ways in which established couples communicate (as described earlier) can enhance or minimize the idealization processes that contribute to such perceptions of one's self or one's partner. Analyzing and explaining the role that these ideal standards have in self- and partner-perceptions is required in order to understand the regulatory behavior that occurs in relationships. As such, the second aim of the current research was to explore how promotion and prevention orientations were associated with self- and partner-perceptions, in addition to examining how these associations may have differed as a function of relationship type. 
Past research has supported that individuals in LDRs engage in more frequent idealization processes than individuals in GCRs (Guerrero et al., 2013). As such, it was predicted that individuals in LDRs would hold a greater degree of partner-IPC and selfIPC than individuals in GCRs (Hypothesis 1A). This hypothesis was only partially supported. Individuals in LDRs reported that they perceived themselves as more consistent with their partners' ideals than did individuals in GCRs; there was no difference between relationship types in the degree to which individuals perceived their partner as being consistent with their own ideals, however. Though these results may prompt questioning as to why individuals in LDRs report a greater degree of self-IPC, but not partner-IPC, than individuals in GCRs, I would argue that this would not correctly frame the results obtained. The primary analyses of means indicated that individuals in GCRs and individuals in LDRs reported a high degree of partner-IPC and self-IPC. That is, regardless of relationship type, individuals perceived themselves and their partners as being highly consistent with each other's ideals. The question I would argue that is pertinent to interpreting these results, then, is why individuals in GCRs are now (compared to earlier years; Stafford \& Merolla, 2007) reporting just as much partneridealization, but not self-idealization, as individuals in LDRs.

Though further research is needed to fully respond to such a question, I believe part of the answer lies within the association between relationship communication and relationship perceptions in GCRs. As previously estimated, GCR partners now have the ability to stay in hyperconnection and synchrony with each other, in turn fostering communication intimacy. This is primarily accomplished through the use of cell phones, specifically by way of texting. As displayed in Figure 1, texting is the most frequent 
communication mode utilized by individuals in GCRs, beyond that of even face-to-face interaction. Though overall CMC intimacy was not associated with partner-IPC for those in GCRs, exploratory analyses indicated a positive relationship between texting intimacy and Partner-IPC (see Table 3). Thus, I posit that the intimacy generated through texting enhances partner-idealization processes in GCRs to the level of those existing in LDRs, which explains the null result of partner-IPC found between relationship types. 
Table 3

Correlations among the Intimacy of CMC Modes and Relationship Perceptions

\begin{tabular}{|c|c|c|c|c|c|c|c|}
\hline CCR & (1) & $(2)$ & (3) & (4) & $(5)$ & $(6)$ & $(7)$ \\
\hline \multicolumn{8}{|l|}{ Mode of $C M C$} \\
\hline (1) Phone Calls & --- & .18 & .20 & $.42 * * *$ & .19 & .08 & .04 \\
\hline (2) Texting & & --- & $.54 * * *$ & .17 & $.35 *$ & $.22 *$ & $.20 *$ \\
\hline (3) Social Media & & & --- & .24 & .69 & .14 & .12 \\
\hline (4) Video Chat & & & & --- & .07 & .12 & .02 \\
\hline (5) Email & & & & & --- & .06 & .04 \\
\hline \multicolumn{8}{|l|}{ Perceptions } \\
\hline (6) Partner-IPC & & & & & & --- & $.56 * * *$ \\
\hline (7) Self-IPC & & & & & & & --- \\
\hline LDR & (1) & (2) & (3) & (4) & $(5)$ & (6) & $(7)$ \\
\hline \multicolumn{8}{|l|}{ Mode of $C M C$} \\
\hline (1) Phone Calls & --- & $.36 * *$ & $.38 * *$ & $.52 * * *$ & .20 & -.04 & -.03 \\
\hline (2) Texting & & --- & $.52 * * *$ & $.43 * * *$ & .18 & .04 & $.27 *$ \\
\hline (3) Social Media & & & --- & $.44 * * *$ & $.53 * *$ & -.16 & .08 \\
\hline (4) Video Chat & & & & --- & .31 & .13 & .16 \\
\hline (5) Email & & & & & --- & -.25 & -.16 \\
\hline \multicolumn{8}{|l|}{ Perceptions } \\
\hline (6) Partner-IPC & & & & & & --- & $.63 * * *$ \\
\hline (7) Self-IPC & & & & & & & --- \\
\hline
\end{tabular}


Why, then, did individuals in LDRs report a slightly greater degree of self-IPC than did individuals in GCRs? The degree of intimacy from texting was a significant predictor of self-IPC in GCRs (explaining the still large degree of self-idealization); however, it was a stronger predictor of self-IPC in LDRs (see Table 3). Though texting intimacy did not differ as a function of relationship type, it is likely that texting fosters communication intimacy between LDR partners in a different way than GCR partners. Whereas communication intimacy may be increased in GCRs by the breadth of topics covered through texting, it is likely the depth of topics disclosed through texting that fosters communication intimacy in LDRs; this idea is consistent with social penetration theory (Altman \& Taylor, 1973), which states that both the breadth and depth of communication aid in relationship maintenance processes. It is likely that individuals in LDRs, compared to individuals in GCRs, discuss more emotionally close and private topics through texting - the primary mode of communication reported by participants in LDRs (see Figure 1) - than any other mode of CMC. Furthermore, long-distance partners have the ability to engage in strategic self-presentation during these deeper communications (Stafford \& Merolla, 2007). This heightened control over the intimacy conveyed in these texts allows individuals in LDRs to present what they believe is their ideal self to their partners, thus enhancing their self-IPC to a marginally greater degree than individuals in GCRs.

Regarding the role that promotion and prevention orientations play in predicting partner- and self-idealization, the following was hypothesized: degree of promotion focus would be negatively associated with partner-IPC (Hypothesis 2B) and degree of prevention focus would be negatively associated with self-IPC (Hypothesis 2C). Contrary 
to Hypothesis 2B, participants' degree of prevention focus, not promotion focus, was negatively associated with their reported partner-IPC. Degree of promotion focus was actually positively associated with partner-IPC; that is, the higher participants' degree of promotion focus, the more likely they were to perceive their partners as being consistent with their ideals. Hypothesis $2 \mathrm{C}$ was also not supported, as there was no significant relationship between participants' degree of prevention focus and their reported self-IPC. Degree of promotion focus, however, did significantly predict self-IPC; the higher participants' degree of promotion focus, the more likely they were to perceive their selves as being consistent with their partners' ideals. These results are discrepant from Lackenbauer and Campbell (2012), who found that individuals assigned to a partnerdiscrepancy prime embraced promotion-focused tactics of emotion regulation, while individuals assigned to a self-discrepancy prime embraced prevention-focused tactics of emotion regulation.

These results may be contradictory because the participants in Lackenbauer and Campbell's (2012) study were first asked to list ways in which either (a) their partner was discrepant from their ideals, or (b) they were discrepant from their partners' ideals. Only after this were outcomes related to regulatory focus assessed. In the current study, regulatory focus was measured before partner-IPC or self-IPC, thus left uninfluenced by perceptions of partner- or self-discrepancies. Had regulatory focus been measured after reports of partner-IPC and self-IPC, it is possible that participants who reported a high number of partner-discrepancies would have reported a large degree of promotion focus in their regulatory orientation; likewise, participants who would have reported a high number of self-discrepancies would have reported a large degree of prevention focus in 
their regulatory orientation. It is important to again note that regulatory focus is a fluid state of mind that can shift to be more promotion- or prevention-oriented based on the situations with which one is faced (Higgins, 1997); this fluidity explains the results found by Lackenbauer and Campbell (2012), who primed individuals with only partnerdiscrepant or self-discrepant perceptions.

While regulatory focus is fluid and can shift in varying circumstances, one's overall regulatory orientation remains relatively stable across life. As stated, individuals have been found to resort to their preferred regulatory style across a variety of goal pursuits (Higgins et al., 2001). As the regulatory focus of participants in the current study was assessed before testing their maintenance efforts (i.e., communication, perceptions, behavior), it is likely that their more stable orientations were measured. It can be assumed, then, that the results found in the current study are accurate. That is, those with a high degree of promotion focus, compared to those with a low degree, perceive their partners and their selves as being more consistent with each other's ideals. Highly promotion-focused individuals may be especially motivated to perceive ideal-consistent qualities in their partner and self because of their orientation toward achieving positive outcomes in life. This fixation on positive outcomes has been found to cloud these individuals' perceptions of their partner's dissatisfaction (Grant \& Higgins, 2003), which can explain the ideal-consistent perceptions found in the current study. While one's degree of promotion focus predicted ideal-consistent perceptions of one's partner, degree of prevention focus predicted ideal-discrepant partner perceptions. Highly preventionfocused individuals are especially concerned with preventing negative outcomes in their relationships. When such outcomes are not prevented, they experience agitation and 
frustration (Stein \& Jewett, 1982; Winterheld \& Simpson, 2011). These emotions could be projected onto these individuals' partners, rather than their selves, resulting in more partner-discrepant (but not self-discrepant) perceptions.

\section{Relationship Behavior: The Misconception of Independence}

Before presenting a discussion of the results found in regard to relationship behavior, I must note a misconception made in formulating hypotheses. Behavioral regulation occurs in response to an ideal-discrepant perception (Overall \& Simpson, 2013; Rusbult et al., 2005). Accordingly, partner-regulation should occur in response to perceived partner-discrepancies from one's ideals (i.e., a low partner-IPC) and selfregulation should occur in response to perceived self-discrepancies from one's partner's ideals (i.e., a low self-IPC). Unfortunately, this imperative notion was not taken into account when generating hypotheses on relationship behavior. Instead, hypotheses on relationship behavior were made independent of hypotheses on relationship perceptions. As such, the majority of what follows will focus on how the results found were consistent with and dependent upon the findings of relationship perceptions, rather than how findings were results did not support the hypotheses made.

The same pattern of results was found in comparing relationship types in their degree of relationship behavior as their degree of relationship perceptions. Individuals in GCRs did not differ from individuals in LDRs in their degree of partner-regulation; those in LDRs, however, did enact a moderately lesser degree of self-regulation than those in GCRs (though the degree of self-regulation was relatively low for both relationship types). Tying this back to the earlier discussion of results, it is likely that individuals in LDRs engage in more emotionally close and private conversations through CMC, 
especially via texting. These communications give individuals in LDRs, compared to individuals in GCRs, the increased ability to present what they believe is their ideal self to their partner. Because of their increased ideal-consistent self-perceptions, individuals in LDRs have less reason than individuals in GCRs to engage in self-regulatory behavior. Just as relationship behavior operated in tandem with relationship perceptions as a function of relationship type, so did the relationship between these variables operate as a function of regulatory focus. Individuals with a high degree of promotion focus, compared to those with a low degree, perceived both their partner and their self as being more consistent with each other's ideals; accordingly, individuals with a high degree of promotion focus engaged in less behavioral regulation of their partner and their self. The opposite effect emerged for those high in their degree of prevention focus - the highly prevention-focused participants perceived their partners as being less consistent with their ideals and, as such, enacted more partner-regulatory behavior.

The only association that was not consistent with this perception-behavior link was that between degree of prevention focus and self-regulation. Though degree of prevention focus had no effect on self-IPC, those with a high degree of prevention focus did enact more self-regulatory behavior than those with a low degree of prevention focus. Although this effect was in support of Hypothesis 3C, less is clear about why this effect was not also coupled with a significant association between degree of prevention focus and self-IPC. That is, why do those with a high degree of prevention focus perceive themselves just as consistent with their partners' ideals as those with a low degree of prevention focus, yet still enact more self-regulatory behavior? It is highly possible that the self-regulatory behavior enacted by highly prevention-focused individuals is 
motivated by factors outside of the relationship. Note again that those with a strong degree of prevention focus are oriented towards security in their life - maintaining positive aspects, while preventing negative aspects. Many ideals require a greater degree of self-regulation in order to be perceived as at a satisfactory level. For example, a highly prevention-focused individual could perceive his or her body and health to be consistent with what his or her partner wants. However, in order to maintain this ideal-consistent perception, this individual may self-regulate more often (e.g., go to the gym, eat less unhealthy food) than an individual with a low-degree of prevention focus. This idea is one that should be applied to all of the results of the current study - though motivation for communication, perceptions, and behavior in a relationship are based largely on one's partner, these maintenance behaviors can also be in response to internal motivations and other outside factors.

\section{Limitations, Strengths, and Directions for Future Research}

The current study was not without limitations. First, this study was nonexperimental; thus, causality and directionality cannot be determined. Though regulatory focus is broadly theorized as characterizing - and being a prerequisite of - one's motivation for relationship maintenance efforts (Lackenbauer \& Campbell, 2012; Overall et al., 2013), it is likely that these associations are not unidirectional. As Higgins et al. (2011) found, one's regulatory orientation can be reinforced by successful goal pursuits. Thus, while certain associations were found in the current research (e.g., degree of prevention focus being a positive predictor of partner-regulation), these variables may not be operating in tandem (e.g., successful partner-regulation could further instill one's degree of prevention focus). Future research can benefit from testing these associations 
via an experimental approach (i.e., priming studies) to determine causality and directionality.

Second, it must be noted that one of the items used to measure prevention focus ("I often imagine myself experiencing bad things [e.g., rejection, betrayal, pain] that I fear might happen in my relationships") was inadvertently left off the survey that all participants completed. As such, definitive claims and comparisons to past research regarding the role of a prevention orientation in romantic relationships cannot be made without a small degree of error. Internal consistency of the remaining six items that measured prevention focus, however, was adequate $(\alpha=.79)$. It is estimated that had the missing item been included, that results would have been in a similar pattern.

This study could have also benefited from including various other items that assessed participants' relationship satisfaction and history. Relationship satisfaction has been found to be associated with relationship communication (Kirk, 2013; Morey et al., 2013), perceptions (Overall et al., 2006; Overall et al., 2010), and behavior (Fitzsimons \& Finkel, 2010; Overall \& Simpson, 2013) for both GCRs and LDRs. Further, one's motivation for relationship satisfaction can vary, depending on her or his degree of promotion or prevention orientations. Whereas highly promotion-focused individuals often engage in processes in hopes of increasing relationship satisfaction, highly prevention-focused individuals are motivated to avoid declines in their satisfaction (Lackenbauer \& Campbell, 2012). In the current study, relationship satisfaction could have served as a relevant moderator and outcome variable of the associations found.

Regarding relationship history, nothing was asked to assess the duration of participants' specific relationship type. It is possible that some individuals who classified 
themselves as being in a LDR began their current relationship being geographicallyclose; likewise, some individuals who classified themselves as being in a GCR may have once maintained their relationship from a distance. It is possible that these types of relationship partners differ from those whose relationships' are, and have always been, exclusively geographically-close or long-distance. Similar to the notion of relationship history, developmental considerations were not tested for in the current research. Married couples have been found to use more prevention-focused maintenance styles than dating couples; similarly, there is a positive relationship between age and implementation of prevention-focused methods as means for goal attainment (Berscheid \& Regan, 2005). Future research should explore the impact that relationship history and developmental changes in relationship status and age may have on the associations found in the current study.

Despite these limitations, the current study also has strengths. First, although I was unable to replicate the findings of Lackenbauer and Campbell (2012) regarding regulatory orientations predicting relationship perceptions, the results in the current study further expound and extend this association. That is, whereas Lackenbauer and Campbell measured promotion and prevention orientations after having participants respond to a partner-discrepancy or self-discrepancy prime, I measured regulatory focus before participants' partner- and self-discrepancies were measured. This order of measures isolated the effect of promotion and prevention orientations on relationship perceptions, thus elucidating how one's more chronic - opposed to temporary - regulatory focus motivates her or his partner- and self-perceptions. Moreover, comparing the current findings to those of Lackenbauer and Campbell further supports past research that has 
found regulatory focus to be fluid, depending upon the circumstances with which one is faced. For instance, whereas a high degree of promotion focus can positively predict ideal-consistent perceptions of one's self (as found in the current study), being primed with the idea of how one's self is discrepant from her or his partner's ideals can elicit a more prevention-focused orientation (as found by Lackenbauer and Campbell).

Beyond finding how one's degree of promotion and prevention orientations predict how she or he perceives their relationship, the current research filled in a gap that past research on regulatory focus had not explored - its relationship with the communication in one's relationship. While degree of promotion focus was found to be a positive predictor of CMC intimacy, degree of prevention focus was found to be a negative predictor of CMC quantity. These findings may help relationship partners better understand each other if their dominant orientations are in opposition. Individuals with highly promotion-focused partners can benefit from interpreting their desires to enact more intimate affections over $\mathrm{CMC}$ as a means to facilitate relationship growth, rather than questioning if such affections are genuine. In turn, individuals with highly prevention-focused partners can benefit from interpreting their avoidance of communications over $\mathrm{CMC}$ as a means to keep the relationship stable and secure, rather than questioning if such avoidance may indicate a problem in the relationship. While replication of such findings is needed, having relationship partners discuss their motivations for communication over CMC may be a beneficial route for future research aimed at bolstering communication satisfaction in both GCRs and LDRs.

The communication efforts found between these two relationship types sheds light on perhaps the major strength of this research: giving partial evidence as to how 
communication technology development in the past decade has benefited each relationship type. While no difference was expected between the relationship types in terms of the quantity of their communication efforts, individuals in LDRs were found to report more frequent communication efforts than individuals in GCRs; this difference was driven by newly developed communication technologies (i.e., video chat, social media messaging), which have recently given long-distance partners a greater ability than ever before to maintain the communication in their relationship. Alternatively, and equally unexpected, the participants in GCRs were found to report just as much intimacy in their communication efforts as the participants in LDRs. I argue that, while these newer communication technologies have enhanced the communication options of LDR partners, they have increased the interconnectedness that is possible between GCR partners. Individuals in proximal relationships now have the ability to stay hyperconnected to each other, being better able to communicate anytime and anywhere. Indeed, the current research is greatly strengthened by its evidence for how the technological advancements in the past decade have changed the communication efforts in each type of relationship. This gives strong support to the notion that a large percentage of earlier research on this topic is no longer reliable; as such, updated research is needed to test the effects of communication technologies on romantic relationships. One specific direction could be to further investigate how texting - found to be an important mode of communication in predicting relationship perception in the current study - differentially operates between relationship types in facilitating CMC intimacy. 


\section{Concluding Remarks}

Relationship maintenance can be a consuming task for any individual, regardless of the type of her or his relationship or dominant motivational orientation. One of the four conceptualizations of relationship maintenance that Davis (1973) proposed was that individuals attempt to repair their relationship when it fluctuates from the standard they hold for an ideal relationship; further, these reparations can be done through corrective (i.e., promotion-focused) or preventative (i.e., prevention-focused) manners. The current research explored these reparation efforts through individuals' reports of their relationship communications, perceptions, and behaviors, while also comparing these maintenance efforts between individuals in geographically-close or long-distance relationships. Overall, it was found that individuals in LDRs, compared to individuals in GCRs, engaged in more frequent communication efforts, more self-idealized perceptions, and less self-regulation behaviors. Regarding regulatory orientations, those with a high degree of promotion focus, compared to those with a low degree of promotion focus, reported more intimate communication, more idealized perceptions of their partners and their selves, and less behavioral regulation of their partners and their selves.

Alternatively, those with a high degree of prevention focus, compares to those with a low degree of prevention focus, reported less frequent communication, less partner-idealized perceptions, and more behavioral regulation of their partners and their selves. While the role of participants' regulatory focus in predicting relationship maintenance efforts did not appear to differ between the relationship types, it is hoped that the results found in the current study can not only expand, but further elucidate, current knowledge in the fields of relationship and motivational science. Further research can aid in helping relationship 
partners utilize their motivational orientations to engage in productive maintenance efforts, whether near or far. 


\section{REFERENCES}

Altman, I., \& Taylor, D. (1973). Social penetration theory. In I. Altman \& D. Taylor (Eds.), Social penetration: The development of interpersonal relationships. Oxford, England: Holt, Rinehart, \& Winston.

Berscheid, E., \& Regan, P. C. (2005). The psychology of interpersonal relationships. New York: Prentice Hall.

Billedo, C. J., Kerkhof, P., \& Finkenauer, C. (2015). The use of social networking sites for relationship maintenance in long-distance and geographically close romantic relationships. Cyberpsychology, Behavior, and Social Networking, 18, 152-157.

Bochner, A. P. (1984). The functions of human communication in interpersonal bonding. In C. C. Arnold \& J. W. Bowers (Eds.), Handbook of rhetorical and communication theory (pp. 544-621). Newton, MA: Allyn and Bacon.

Bohns, V. K., \& Higgins, E. T. (2011). Liking the same things, but doing things differently: Outcome versus strategic compatibility in partner preferences for joint tasks. Social Cognition, 29, 497-527.

Bohns, V. K., Lucas, G. M., Molden, D. C., Finkel, E. J., Coolsen, M. K., Kumashiro, M., \& Higgins, E. T. (2013). Opposites fit: Regulatory focus complementarity and relationship well-being. Social Cognition, 31, 1-14.

Cameron, J. J., \& Ross, M. (2007). The times of uncertainty: Predicting the survival of long-distance relationships. Journal of Social Psychology, 147, 581-606. 
Campbell, L., Simpson, J. A., Kashy, D. A., \& Fletcher, G. J. (2001). Ideal standards, the self, and flexibility of ideals in close relationships. Personality and Social Psychology Bulletin, 27, 447-462.

Cemalcilar, Z. (2008). Communicating electronically when too far away to visit. In S. Kelsey, \& K. St. Amant (Eds.), Handbook of Research on Computer Mediated Communication (pp. 365-378). Hershey, PA: Information Science Reference. comScore (2008). Happy anniversary, M:Metrics [press release]. Retrieved from comScore website: https://www.comscore.com/Insights/PressReleases/2008/03/M-Metrics-Anniversary comScore (2016). comScore Reports December 2015 U.S. Smartphone Subscriber Market Share [market rankings]. Retrieved from comScore website: https://www.comscore.com/Insights/Market-Rankings/comScore-ReportsDecember-2015-US-Smartphone-Subscriber-Market-Share

Coyne, S. M., Stockdale, L., Busby, D., Iverson, B., \& Grant, D. M. (2011). “I luv u:)!”: A descriptive study of the media use of individuals in romantic relationships. Family Relations, 60, 150-162.

Dainton, M., \& Aylor, B. (2001). A relational uncertainty analysis of jealousy, trust, and maintenance in long-distance versus geographically close relationships. Communication Quarterly, 49, 172-188.

Dainton, M., \& Aylor, B. (2002). Patterns of communication channel use in the maintenance of long-distance relationships. Communication Research Reports,19, 118-129. 
Dainton, M., \& Stafford, L. (1993). Routine maintenance behaviors: A comparison of relationship type, partner similarity and sex differences. Journal of Social and Personal Relationships, 10, 255-271.

Davis, M. S. (1973). Intimate relations. New York, NY: Free Press.

Dindia, K., \& Canary, D. S. (1993). Definitions and theoretical perspectives on maintaining relationships. Journal of Social and Personal Relationships, 10, 163173.

Duck, S. W., \& Pittman, G. (1994). Social and personal relationships. In M. L. Knapp, \& G. R. Miller (Eds.), Handbook of interpersonal communication (pp. 676-695). Thousand Oaks, CA: SAGE Publications.

Firmin, M. W., Firmin, R. L., \& Merical, K. L. (2013). Extended communication efforts involved with college long-distance relationships. Contemporary Issues in Education Research, 6, 97-110.

Fitzsimons, G. M., \& Finkel, E. J. (2010). Interpersonal influences on selfregulation. Current Directions in Psychological Science, 19, 101-105.

Fitzsimons, G. M., \& Finkel, E. J. (2011). Outsourcing self-regulation. Psychological Science, 22(3), 369-375.

Fletcher, G. J., Simpson, J. A., Thomas, G., \& Giles, L. (1999). Ideals in intimate relationships. Journal of personality and social psychology, 76, 72-89.

Fletcher, G. J. O., \& Thomas, G. (2000). Behavior and on-line cognition in marital interaction. Personal Relationships, 7, 111-130. 
Grant, H., \& Higgins, E. T. (2003). Optimism, promotion pride, and prevention pride as predictors of quality of life. Personality and Social Psychology Bulletin, 29, 15211532.

Guerrero, L. K., Andersen, P. A., \& Afifi, W. A. (2013). Close encounters: Communication in relationships. Thousand Oaks, CA: Sage Publications.

Guldner, G. (2003). Long distance relationships: The complete guide. Corona, CA: JF Milne Publications.

Guldner, G. T., \& Swensen, C. H. (1995). Time spent together and relationship quality: Long-distance relationships as a test case. Journal of Social and Personal Relationships, 12, 313-320.

Helgeson, V. S. (1994). Long-distance romantic relationships: Sex differences in adjustment and breakup. Personality and Social Psychology Bulletin, 20, 254265.

Higgins, E. T. (1987). Self-discrepancy: A theory relating self and affect. Psychological Review, 94, 319-340.

Higgins, E. T. (1989). Self-discrepancy theory: What patterns of self-beliefs cause people to suffer? In L. Berkowitz (Ed.), Advances in experimental social psychology. New York: Academic Press.

Higgins, E. T. (1996a). Ideals, oughts, and regulatory focus: Affect and motivation from distinct pains and pleasures. In P. M. Gollwitzer and J. A. Bargh (Eds.), The psychology of action: Linking cognition and motivation to behavior (pp. 91-114). New York: Guilford Press. 
Higgins, E. T. (1996b). The" self digest": self-knowledge serving self-regulatory functions. Journal of personality and social psychology, 71, 1062-1083.

Higgins, E. T. (1997). Beyond pleasure and pain. American psychologist, 52, 1280-1300.

Higgins, E. T. (1998). Promotion and prevention: Regulatory focus as a motivational principle. Advances in experimental social psychology, 30, 1-46.

Higgins, E. T., Friedman, R. S., Harlow, R. E., Idson, L. C., Ayduk, O. N., Taylor, A. (2001). Achievement orientations from subjective histories of success: Promotion pride versus prevention pride. European Journal of Social Psychology, 31, 3-23.

Jiang, L. C., Bazarova, N. N., \& Hancock, J. T. (2013). From perception to behavior: Disclosure reciprocity and the intensification of intimacy in computer-mediated communication. Communication Research, 40, 125-143.

Jiang, L. C., \& Hancock, J. T. (2013). Absence makes the communication grow fonder: Geographic separation, interpersonal media, and intimacy in dating relationships. Journal of Communication, 63, 556-577.

Kelmer, G., Rhoades, G. K., Stanley, S., \& Markman, H. J. (2013). Relationship Quality, Commitment, and Stability in Long-Distance Relationships. Family process, 52, 257-270.

Kirk, A. (2013). The effect of newer communication technologies on relationship maintenance and satisfaction in long-distance relationships. Pepperdine Journal of Communication Research, 1, 3-7. Retrieved from http://digitalcommons.pepperdine.edu/pjcr/vol1/iss $1 / 2$ 
Kirkpatrick, D. C. (2007). Predictors of relational satisfaction and intimacy in the computer-mediated communication of romantic partners (Master's thesis). The University of Iowa, Iowa City, IA.

Lackenbauer, S. D., \& Campbell, L. (2012). Measuring up: The unique emotional and regulatory outcomes of different perceived partner-ideal discrepancies in romantic relationships. Journal of Personality and Social Psychology, 103, 472-488.

The Center for the Study of Long Distance Relationships (2005). Retrieved from http://www.longdistancerelationships.net/

Maguire, K. C., \& Kinney, T. A. (2010). When distance is problematic: Communication, coping, and relational satisfaction in female college students' long-distance dating relationships. Journal of Applied Communication Research, 38, 27-46.

Merolla, A. J. (2010). Relational maintenance and noncopresence reconsidered: Conceptualizing geographic separation in close relationships. Communication Theory, 20, 169-193.

Merolla, A. J. (2012). Connecting here and there: A model of long-distance relationship maintenance. Personal Relationships, 19, 775-795.

Miller-Ott, A. E., Kelly, L., \& Duran, R. (2012). The effects of cell phone usage rules on satisfaction in romantic relationships. Communication Quarterly, 60, 17-34.

Molden, D. C., \& Finkel, E. J. (2010). Motivations for promotion and prevention and the role of trust and commitment in interpersonal forgiveness. Journal of Experimental Social Psychology, 46, 255-268.

Molden, D. C., Lucas, G. M., Finkel, E. J., Kumashiro M., \& Rusbult, C. (2009). Perceived support for promotion-focused and prevention-focused goals: 
Associations with well-being in unmarried and married couples. Psychological Science, 20, 787-793.

Morey, J. N., Gentzler, A. L., Creasy, B., Aberhauser, A. M., \& Westerman, D. (2013). Young adults' use of communication technology within their romantic relationships and associations with attachment style. Computers in Human Behavior, 29, 1771-1778.

Murray, S. L., \& Holmes, J. G. (1997). A leap of faith? Positive illusions in romantic relationships. Personality and Social Psychology Bulletin, 23, 586-604.

Neustaedter, C., \& Greenberg, S. (2012). Intimacy in long-distance relationships over video chat. Paper presented at the SIGCHI Conference on Human Factors in Computing Systems, Austin, TX (pp. 753-762).

Overall, N. C., Fletcher, G. J., \& Simpson, J. A. (2006). Regulation processes in intimate relationships: The role of ideal standards. Journal of Personality and Social Psychology, 91, 662-685.

Overall, N. C., Fletcher, G. J., \& Simpson, J. A. (2010). Helping each other grow: Romantic partner support, self-improvement, and relationship quality. Personality and Social Psychology Bulletin, 36, 1496-1513.

Overall, N. C., \& Sibley, C. G. (2008). Attachment and attraction toward romantic partners versus relevant alternatives within daily interactions. Personality and Individual Differences, 44, 1126-1137.

Overall, N. C., \& Simpson, J. A. (2013). Regulation Processes in Close Relationships. In J. A. Simpson, \& L. Campbell (Eds.), The Oxford handbook of close relationships (pp. 427-451). Oxford, NY: Oxford University Press. 
Piers, G., \& Singer, M. B. (1971). Shame and guilt. New York: Norton.

Pistole, M. C. (2010). Long-distance romantic couples: An attachment theoretical perspective. Journal of Marital and Family Therapy, 36, 115-125.

Rogers, C. R. (1961). On becoming a person: A therapist's view of psychology.

Rohlfing, M. E. (1995). Doesn't anybody stay in one place anymore? An exploration of the understudied phenomenon of long-distance relationships. In J. T. Wood \& S. E. Duck (Eds.), Under-studied relationships: Off the beaten track (pp. 173-196). Thousand Oaks, CA: Sage Publications.

Roseman, I. J. (1984). Cognitive determinants of emotion: A structural theory. Review of Personality and Social Psychology, 5, 11-36.

Ruppel, E. K. (2015). Use of communication technologies in romantic relationships: Selfdisclosure and the role of relationship development. Journal of Social and Personal Relationships, 32, 667-686.

Rusbult, C. E., Kumashiro, M., Stocker, S. L., \& Wolf, S. T. (2005). The Michelangelo phenomenon in close relationships. In A. Tesser, J. V. Wood, \& D. A. Stapel (Eds.), On building, defending, and regulating the self: A psychological perspective (pp. 1-29). New York, NY: Psychology Press.

Rusbult, C. E., Verette, J., Whitney, G. A., Slovik, L. F., \& Lipkus, I. (1991). Accommodation processes in close relationships: Theory and preliminary empirical evidence. Journal of Personality and Social Psychology, 60, 53-78.

Sahlstein, E. M. (2004). Relating at a distance: Negotiating being together and being apart in long-distance relationships. Journal of Social and Personal Relationships, 21, 689-710. 
Sahlstein, E. M. (2006). The trouble with distance. In D. C. Kirkpatrick, S. D. Duck, \& M. K. Foley (Eds.), Relating difficulty: The process of constructing and managing difficult relationships (pp. 119-140). Mahwah, NJ: Erlbaum.

Shah, J. (2003). Automatic for the people: How representations of significant others implicitly affect goal pursuit. Journal of Personality and Social Psychology, 84, $661-681$.

Simpson, J. A., Fletcher, G. J., \& Campbell, L. (2001). The structure and function of ideal standards in close relationships. In G. J. Fletcher \& M. S. Clark (Eds.), Blackwell Handbook of Social Psychology: Interpersonal Processes (pp. 86-106). Blackwell Publishers Ltd.

Stafford, L. (2010). Geographic distance and communication during courtship. Communication Research, 37, 275-297.

Stafford, L., \& Hillyer, J. D. (2012). Information and communication technologies in personal relationships. The Review of Communication, 12, 290-312.

Stafford, L., \& Merolla, A. J. (2007). Idealization, reunions, and stability in long-distance dating relationships. Journal of Social and Personal Relationships, 24, 37-54.

Stafford, L., \& Reske, J. R. (1990). Idealization and communication in long-distance premarital relationships. Family relations, 39, 274-279.

Stein, N. L., \& Jewett, J. L. (1982). A conceptual analysis of the meaning of negative emotions: Implications for a theory of development. In C. E. Izard (Ed.), Measuring emotions in infants and children (pp. 401-443). New York: Cambridge University Press. 
Stewart, M. C., Dainton, M., \& Goodboy, A. K. (2014). Maintaining relationships on Facebook: Associations with uncertainty, jealousy, and satisfaction. Communication Reports, 27, 13-26.

Toma, C. L., \& Choi, M. (2015). The couple who Facebooks together, stays together: Facebook self-presentation and relationship longevity among college-aged dating couples. Cyberpsychology, Behavior, and Social Networking, 18, 367-372.

Van Horn, K., Arnone, A., Nesbitt, K., Desillets, L., Sears, T., Giffin, M., \& Brudi, R. (1997). Physical distance and interpersonal characteristics in college students' romantic relationships. Personal Relationships, 4, 25-34.

Walther, J. B. (1996). Computer-mediated communication impersonal, interpersonal, and hyperpersonal interaction. Communication research, 23, 3-43.

Winterheld, H. A., \& Simpson, J. A. (2011). Seeking security or growth: Regulatory focus perspective on motivations in romantic relationships. Journal of Personality and Social Psychology, 101, 935-954. 


\section{FOOTNOTES}

${ }^{1}$ In consideration of the motivational contexts for such maintenance strategies, those in a dating relationship have been found to be primarily focused on attainment (Berscheid \& Regan, 2005). In contrast, Berscheid and Regan (2005), note that the motivational context for married couples is broader than the more narrow scope of dating couples; that is, in addition to their consideration of attainment (i.e., promotion-focused means) in their relationship, married couples are more likely than dating couples to evaluate their relationship in terms of the security it provides for themselves (i.e. prevention-focused means).

${ }^{2}$ Individuals who were in LDRs and currently visiting their partner were omitted from the initial sample. Past research has supported that individuals in LDRs behave differently, or are on their best relational behavior, when visiting their partners compared to when they are at a distance (e.g., Guerrero et al., 2013).

${ }^{3}$ Mahalanobis distance was calculated. Extreme multivariate outliers were eliminated.

${ }^{4}$ The Regulatory Focus in Relationships Scale has 15 items. One of the prevention items ("I often imagine myself experiencing bad things [e.g., rejection, betrayal, pain] that I fear might happen in my relationships") was inadvertently left off the survey. ${ }^{5}$ Participants were not omitted from data analysis if they responded to one item inaccurately, due to the chance of incorrectly matching up the question to the scale. Most 
participants who inaccurately responded to a question responded at the opposite end of the scale (e.g., "7" instead of "1"). Additionally, participants who responded with "2" to the quality check questions were not omitted, due to the potentiality of some questions (e.g., "How often do you have heart attacks while watching television?").

${ }^{6}$ Face-to-face communication was also assessed but not used in analyses, due to individuals in GCRs naturally having more time spent face-to-face.

${ }^{7}$ In addition to the relationship type $\mathrm{x}$ regulatory focus interactions that were tested, relationship type $\mathrm{x}$ gender and regulatory focus $\mathrm{x}$ gender interactions were also explored. No significant interactions existed for any of the dependent measures. 